OPEN ACCESS

Edited by:

Yu Ru Kou,

National Yang-Ming University, Taiwan

Reviewed by:

David Cristóbal Andrade,

Universidad Mayor, Chile

Julio Alcayaga,

University of Chile, Chile

*Correspondence:

Paulina M. Getsy

pxg55@case.edu

Specialty section:

This article was submitted to Respiratory Physiology, a section of the journal

Frontiers in Physiology

Received: 03 October 2020 Accepted: 25 November 2020

Published: 17 December 2020

Citation:

Getsy PM, Coffee GA and Lewis SJ (2020) The Role of Carotid Sinus Nerve Input in the Hypoxic-Hypercapnic Ventilatory Response in Juvenile Rats.

Front. Physiol. 11:613786. doi: 10.3389/fphys.2020.613786

\section{The Role of Carotid Sinus Nerve Input in the Hypoxic-Hypercapnic Ventilatory Response in Juvenile Rats}

\author{
Paulina M. Getsy ${ }^{1,2 *}$, Gregory A. Coffee ${ }^{1}$ and Stephen J. Lewis ${ }^{1,3}$ \\ 1 Department of Pediatrics, Division of Pulmonology, Allergy and Immunology, Case Western Reserve University, Cleveland, \\ $\mathrm{OH}$, United States, ${ }^{2}$ Department of Physiology and Biophysics, Case Western Reserve University, Cleveland, $\mathrm{OH}$, \\ United States, ${ }^{3}$ Department of Pharmacology, Case Western Reserve University, Cleveland, $\mathrm{OH}$, United States
}

In juvenile rats, the carotid body $(\mathrm{CB})$ is the primary sensor of oxygen $\left(\mathrm{O}_{2}\right)$ and a secondary sensor of carbon dioxide $\left(\mathrm{CO}_{2}\right)$ in the blood. The $\mathrm{CB}$ communicates to the respiratory pattern generator via the carotid sinus nerve, which terminates within the commissural nucleus tractus solitarius (CNTS). While this is not the only peripheral chemosensory pathway in juvenile rodents, we hypothesize that it has a unique role in determining the interaction between $\mathrm{O}_{2}$ and $\mathrm{CO}_{2}$, and consequently, the response to hypoxic-hypercapnic gas challenges. The objectives of this study were to determine (1) the ventilatory responses to a poikilocapnic hypoxic $(H X)$ gas challenge, a hypercapnic $(\mathrm{HC})$ gas challenge or a hypoxic-hypercapnic $(\mathrm{HH})$ gas challenge in juvenile rats; and (2) the roles of CSN chemoafferents in the interactions between $\mathrm{HX}$ and $\mathrm{HC}$ signaling in these rats. Studies were performed on conscious, freely moving juvenile (P25) male Sprague Dawley rats that underwent sham-surgery (SHAM) or bilateral transection of the carotid sinus nerves (CSNX) 4 days previously. Rats were placed in whole-body plethysmographs to record ventilatory parameters (frequency of breathing, tidal volume and minute ventilation). After acclimatization, they were exposed to $\mathrm{HX}\left(10 \% \mathrm{O}_{2}, 90 \%\right.$ $\left.\mathrm{N}_{2}\right), \mathrm{HC}\left(5 \% \mathrm{CO}_{2}, 21 \% \mathrm{O}_{2}, 74 \% \mathrm{~N}_{2}\right)$ or $\mathrm{HH}\left(5 \% \mathrm{CO}_{2}, 10 \% \mathrm{O}_{2}, 85 \% \mathrm{~N}_{2}\right)$ gas challenges for 5 min, followed by 15 min of room-air. The major findings were: (1) the HX, HC and $\mathrm{HH}$ challenges elicited robust ventilatory responses in SHAM rats; (2) ventilatory responses elicited by $\mathrm{HX}$ alone and $\mathrm{HC}$ alone were generally additive in SHAM rats; (3) the ventilatory responses to $\mathrm{HX}, \mathrm{HC}$ and $\mathrm{HH}$ were markedly attenuated in CSNX rats compared to SHAM rats; and (4) ventilatory responses elicited by HX alone and $\mathrm{HC}$ alone were not additive in CSNX rats. Although the rats responded to HX after CSNX, CB chemoafferent input was necessary for the response to $\mathrm{HH}$ challenge. Thus, secondary peripheral chemoreceptors do not compensate for the loss of chemoreceptor input from the $\mathrm{CB}$ in juvenile rats.

\section{Keywords: carotid sinus nerve, hypoxia, hypercapnia, juvenile, rats}

Abbreviations: $\mathrm{CB}$, carotid body; CSN, carotid sinus nerve; CSNX, carotid sinus nerve transection; Freq, frequency of breathing; $\mathrm{HC}$, hypercapnia; $\mathrm{HH}$, hypoxia-hypercapnia; $\mathrm{HX}$, hypoxia; $\mathrm{MV}$, minute ventilation; NTS nucleus tractus solitarius; RTN retrotrapezoid nucleus; VT, tidal volume. 


\section{HIGHLIGHTS}

- Bilateral CSNX blunts, but does not completely block, the hypoxic, hypercapnic and hypoxic-hypercapnic ventilatory responses in juvenile SD rats.

- In SHAM rats, the sum of the responses to hypoxia alone and hypercapnia alone equal the response to hypoxia-hypercapnia.

- In bilateral CSNX rats, the individual ventilatory responses to hypoxia, hypercapnia and hypoxiahypercapnia were similar.

\section{INTRODUCTION}

The detection of oxygen $\left(\mathrm{O}_{2}\right)$, carbon dioxide $\left(\mathrm{CO}_{2}\right)$ and proton $\left(\mathrm{H}^{+}\right)$levels in arterial blood is crucial for the control of breathing (Prabhakar, 2000; Teppema and Dahan, 2010; Guyenet and Bayliss, 2015; Guyenet et al., 2019). Within seconds, arterial hypoxia (low $\mathrm{pO}_{2}$ ), hypercapnia (high $\mathrm{pCO}_{2}$ ) and/or acidosis (high $\mathrm{H}^{+}$levels) stimulate breathing, which is essential for maintaining proper oxygenation of tissues. This ventilatory adjustment depends critically on the $\mathrm{O}_{2}$-sensing ability of the carotid bodies (CBs) and respiratory control brainstem nuclei (Prabhakar, 2000). The CBs are vascularized organs that detect changes in arterial blood $\mathrm{pO}_{2}, \mathrm{pCO}_{2}$ and $\mathrm{pH}$. Decreases in $\mathrm{pO}_{2}$ and $\mathrm{pH}$, and/or elevations in $\mathrm{pCO}_{2}$ stimulate chemosensitive glomus (type I) cells in the CBs to release neurotransmitters that excite closely apposed nerve terminals of chemoafferent fibers within the carotid sinus nerve (CSN), thereby causing an increase in firing of these afferents (Eyzaguirre and Zapata, 1984; Gonzalez et al., 1994; Peers and Buckler, 1995; Prabhakar, 2000; Tse et al., 2012; Kikuta et al., 2019). CSN chemoafferents then relay these signals to the commissural nucleus tractus solitarius (cNTS) within the brainstem (Song et al., 2011), and increased inputs from these chemoafferent fibers trigger downstream responses to restore arterial blood gas status and hemodynamic homeostasis (Prabhakar, 2000; Nurse, 2005, 2010).

The ventilatory responses to hypoxic (HX) and hypercapnic (HC) gas challenges differ in new-born compared to adult animals. In neonates, the HX ventilatory response appears as a biphasic response comprising of a short initial rise in ventilation (augmentation phase) quickly followed by a secondary roll-off, generally to a level below baseline normoxia (depressant phase) (Bureau et al., 1984; McCooke and Hanson, 1985; Eden and Hanson, 1987; Teppema and Dahan, 2010). Shortly after birth in species such as the pig, cat and rat, the initial rise in minute ventilation (MV) is smaller than the secondary roll-off, resulting in lower baseline ventilation values compared to those under normoxia (Bonora et al., 1984; Eden and Hanson, 1987; Elnazir et al., 1996; Liu et al., 2006; Teppema and Dahan, 2010). Once adulthood is reached, the initial rise in ventilation in response to hypoxia is more pronounced and the secondary depression becomes smaller, resulting in a sustained rise in MV (Easton et al., 1986; Vizek et al., 1987; Maxová and Vízek, 2001; Pokorski and Antosiewicz, 2010; Teppema and Dahan, 2010). The ventilatory response to $\mathrm{HC}$ gas challenge during development has been studied extensively in rats and follows a definitive pattern, namely
(1) the ventilatory response to $\mathrm{HC}$ declines (i.e., shows roll-off) during the challenge in the first post-natal week (Stunden et al., 2001; Putnam et al., 2005), (2) the magnitudes of HC responses are at their lowest points during the second week, and (3) the $\mathrm{HC}$ response increases during the third week (i.e., as seen in P21 rats) toward those seen in mature (adult) rats (Stunden et al., 2001; Putnam et al., 2005). The ventilatory response to combined HX and HC (HH) gas challenges (arguably those that induce more physiologically relevant changes in arterial blood-gas chemistry) has not been studied in neonatal rats. However, adult rats exposed to $\mathrm{HH}$ gas challenge show enhanced increases in ventilation compared to HX exposures alone, although whether the responses were greater than $\mathrm{HC}$ gas challenge alone was not determined (Wakai et al., 2015). Nonetheless, the data strongly suggest that $\mathrm{HX}$ and $\mathrm{HC}$ ventilatory signaling may be synergistic in rats (Wakai et al., 2015).

The loss of CSN innervation to the $\mathrm{CB}$ greatly inhibits compensatory respiratory adjustments in response to $\mathrm{HX}$ and HC challenges in neonatal and adult animals. In newborns, the initial rise in ventilation (augmentation phase) in response to acute HX challenge is significantly attenuated after bilateral CSNX (Bureau et al., 1985; Suguihara et al., 1994; Fung et al., 1996; Lowry et al., 1999a,b; Teppema and Dahan, 2010). In adult mammals, bilateral CSNX induces hypoventilation under roomair (Sapru and Krieger, 1977), and diminishes the ventilatory responses to HX and HC challenges (Chalmers et al., 1967; Sapru and Krieger, 1977; Cardenas and Zapata, 1983; Olson et al., 1988; Mouradian et al., 2012; Baby et al., 2018). Within a few weeks after bilateral CSNX there is a noticeable recovery of HX ventilatory responses (Bisgard et al., 1976; Smith and Mills, 1980; Martin-Body et al., 1985, 1986) that are associated with a distinct functional reorganization of central chemoreceptor reflex pathways, including changes in ventilatory pattern and brainstem catecholaminergic activity (Roux et al., 2000). Other reported mechanisms involved in restoration of HX ventilatory response include (1) enhanced aortic body activity (Bisgard et al., 1980; Serra et al., 2002), (2) enhanced chemosensory input from secondary glomus tissue in the head/neck (Martin-Body et al., 1986; Lowry et al., 1999a; Serra et al., 2002), and (3) regeneration of sensory terminals of the carotid sinus nerve, and/or plastic changes in the central respiratory neuronal network involving activation of oxygen-sensing neurons (Smith and Mills, 1980; Lowry et al., 1999b; Serra et al., 2001; Forster, 2003; Mitchell and Johnson, 2003; Teppema and Dahan, 2010).

Along with $\mathrm{CB}$ chemoreceptors, mammalian species also possess central chemoreceptors, such as the retrotrapezoid nucleus (RTN), which play a definitive role in breathing modulation, and are key responders to elevated blood $\mathrm{pCO}_{2}$ (Nattie, 2006; Guyenet and Bayliss, 2015; Guyenet et al., 2019). The CBs detect arterial $\mathrm{pCO}_{2}$ (and $\mathrm{pH}$ ) and monitor alveolar ventilation, whereas central chemoreceptors detect interstitial fluid $\mathrm{pH}$ and monitor the balance of arterial $\mathrm{pCO}_{2}$, cerebral blood flow, and cerebral metabolism (Fencl et al., 1966; Dempsey, 2005; Xie et al., 2005; Smith et al., 2006). The time course of responses varies between central and peripheral chemoreceptors, with CBs providing the rapid response to changes in arterial $\mathrm{pCO}_{2}$, while central chemoreceptors provide most of the steady-state response 
(Smith et al., 2006; Gaston et al., 2014). Studies in conscious humans with intact or surgically resected $\mathrm{CBs}$ revealed that the fast time constant in response to brief $\mathrm{CO}_{2}$ pulses was absent in patients with $\mathrm{CB}$ resection, therefore providing strong support for the rapid response function of the CBs (Fatemian et al., 2003).

Although activation of peripheral or central chemoreceptors causes breathing to increase, the type of interaction between the two systems remains unresolved. It has been hypothesized that when a HX and $\mathrm{HC}$ stimulus are given together, the interaction between the input from both central and peripheral chemoreceptors can be (1) positive in that one stimulus (e.g., HX or HC) augments the effects of the other in a synergistic/multiplicative, manner or (2) negative in that the inputs are hypo-additive (Eldridge et al., 1981). Studies have shown positive or synergistic interaction between $\mathrm{HX}$ and $\mathrm{HC}$ at the level of the CB (Eyzaguirre and Lewin, 1961). Other studies have shown that ventilatory responses to a constant CSN stimulation (mimicking HX exposure), decreased progressively as arterial $\mathrm{pCO}_{2}$ rose (mimicking a $\mathrm{HC}$ exposure), thus suggesting a hypo-additive interaction between the two stimuli (Eldridge, 1974; Kiwull et al., 1976).

Despite evidence that (1) neonatal and adult rats display different $\mathrm{HX}$ and $\mathrm{HC}$ ventilatory responses, and (2) bilateral CSNX blunts HX and HC ventilatory responses in adult and newborn rats, the effects of bilateral CSNX on $\mathrm{HX}, \mathrm{HC}$, or $\mathrm{HH}$ gas challenge in juvenile SD rats are unknown. Moreover, the vital question of how $\mathrm{HX}$ and $\mathrm{HC}$ signaling pathways interact with one another and the role of the CBs in this interaction is not well characterized at any age. To address this, we examined the ventilatory responses elicited by a single 5-min episode of $\mathrm{HX}, \mathrm{HC}$ or $\mathrm{HH}$ gas challenge in conscious, freely moving Sprague Dawley juvenile (postnatal age 25, P25) rats that underwent prior (4 days earlier) sham-operation (SHAM) or bilateral CSNX to disrupt the chemoreceptor reflex pathway. Each gas challenge was given to separate groups of rats (e.g., HX challenge had a group of SHAM and CSNX rats that was separate from the HC and $\mathrm{HH}$ challenge) in order to prevent any confounding influences that one gas challenge may have on the other. Our novel findings demonstrating that CSNX blunts the HX-, HC-, and $\mathrm{HH}$-induced ventilatory responses provide the first in vivo data showing that hyperventilation in response to these challenges in juvenile rats is dependent on CB chemoafferent signaling. Our results also show that the ventilatory responses to $\mathrm{HX}$ alone and HC alone were simply additive in SHAM rats and that this additivity was lost in CSNX rats, suggesting that peripheral $\mathrm{CB}$ chemoafferent activity plays an essential role in determining the interactions between peripheral and central chemoafferent pathways controlling ventilation.

\section{METHODS}

\section{Animals and Surgeries}

All studies were carried out in accordance with the National Institute of Health Guide for the Care and Use of Laboratory Animals (NIH Publication No. 80-23) revised in 1996. The protocols were approved by the Institutional Animal Care and
Use Committee at Case Western Reserve University (Cleveland, $\mathrm{OH}$, United States). Eighty-two male Sprague Dawley (SD) rats (postnatal age 21, P21) from ENVIGO (Indianapolis, IN, United States) were used in these studies. All of the rats were anesthetized with an intraperitoneal injection of ketamine (80 mg/kg, Ketaset, Zoetis, Parsippany, NJ, United States) and xylazine $(10 \mathrm{mg} / \mathrm{kg}$, Akorn Animal Health, Lake Forest, IL, United States), and placed on a surgical station allowing body temperature to be maintained at $37^{\circ} \mathrm{C}$ via a heating pad (SurgiSuite, Kent Scientific Corporation, Torrington, CT, United States). The surgical plane of anesthesia was checked every 15 min by a toe pinch. Bilateral CSNX and sham-operations (SHAM) were performed. For bilateral CSNX, the left and right CSN was transected at the point where they entered their ipsilateral glossopharyngeal nerve (Figure 1) by procedures detailed previously (Gaston et al., 2014; Baby et al., 2018). For the SHAM procedure, the left and right CSN were identified, but not transected. The rats were allowed 4 days to recover from surgery and were P25 on the day of the experimental study.

\section{Recording of Ventilatory Parameters}

Ventilatory parameters were continuously recorded in freely moving P25 juvenile SHAM or bilateral CSNX rats via wholebody plethysmography technology (Buxco ${ }^{\circledR}$ Small Animal Whole Body Plethysmography, DSI a division of Harvard Biosciences, Inc., St. Paul, MN, United States), as detailed previously (Henderson et al., 2013, 2014; May et al., 2013a,b; Baby et al., 2018). All studies were performed in a quiet laboratory with atmospheric pressure of $760 \mathrm{mmHg}$ (sea-level). The chamber volumes were $0.5 \mathrm{~L}$ and the gas flowing through all of the chambers was $0.5 \mathrm{~L} / \mathrm{min}$. The chamber temperatures during the acclimatization period were: SHAM and CSNX rats in HX study (26.6 \pm 0.1 and $26.7 \pm 0.1^{\circ} \mathrm{C}$, respectively $\left.P>0.05\right)$, SHAM and CSNX rats in the $\mathrm{HC}$ study $\left(26.2 \pm 0.2\right.$ and $25.8 \pm 0.2^{\circ} \mathrm{C}$, respectively $P>0.05$ ), and SHAM and CSNX rats in the $\mathrm{HH}$ study $\left(26.3 \pm 0.2\right.$ and $26.3 \pm 0.1^{\circ} \mathrm{C}$, respectively $\left.P>0.05\right)$. The chamber humidities during the acclimatization period were: SHAM and CSNX rats in the HX study $(62.1 \pm 2.4$ and $60.8 \pm 2.0$ $\%$, respectively $P>0.05)$, SHAM and CSNX rats in the HC study $(63.2 \pm 2.5$ and $61.4 \pm 2.5 \%$, respectively $P>0.05)$, and SHAM and CSNX rats in the HH study $(62.8 \pm 1.3$ and $61.1 \pm 1.1 \%$, respectively $P>0.05$ ). Directly recorded parameters used in this manuscript were frequency of breathing ( $f R$ ) and tidal volume (VT). The calculated parameter we used was minute ventilation $(\mathrm{MV})$, which is $(\mathrm{fR} \times \mathrm{VT})$ (Laferrière et al., 2005; Young et al., 2013). The software constantly corrected digitized values for changes in chamber temperature and humidity, and a rejection algorithm excluded motion-induced artifacts (Henderson et al., 2013, 2014; May et al., 2013a,b; Getsy et al., 2014; Baby et al., 2018).

\section{Protocols and Data Recording Including Maximal Attainable Responses}

The rats were placed in plethysmography chambers to continuously record (breath by breath) ventilatory parameters. The rats were allowed to acclimatize for at least $60 \mathrm{~min}$ to allow 


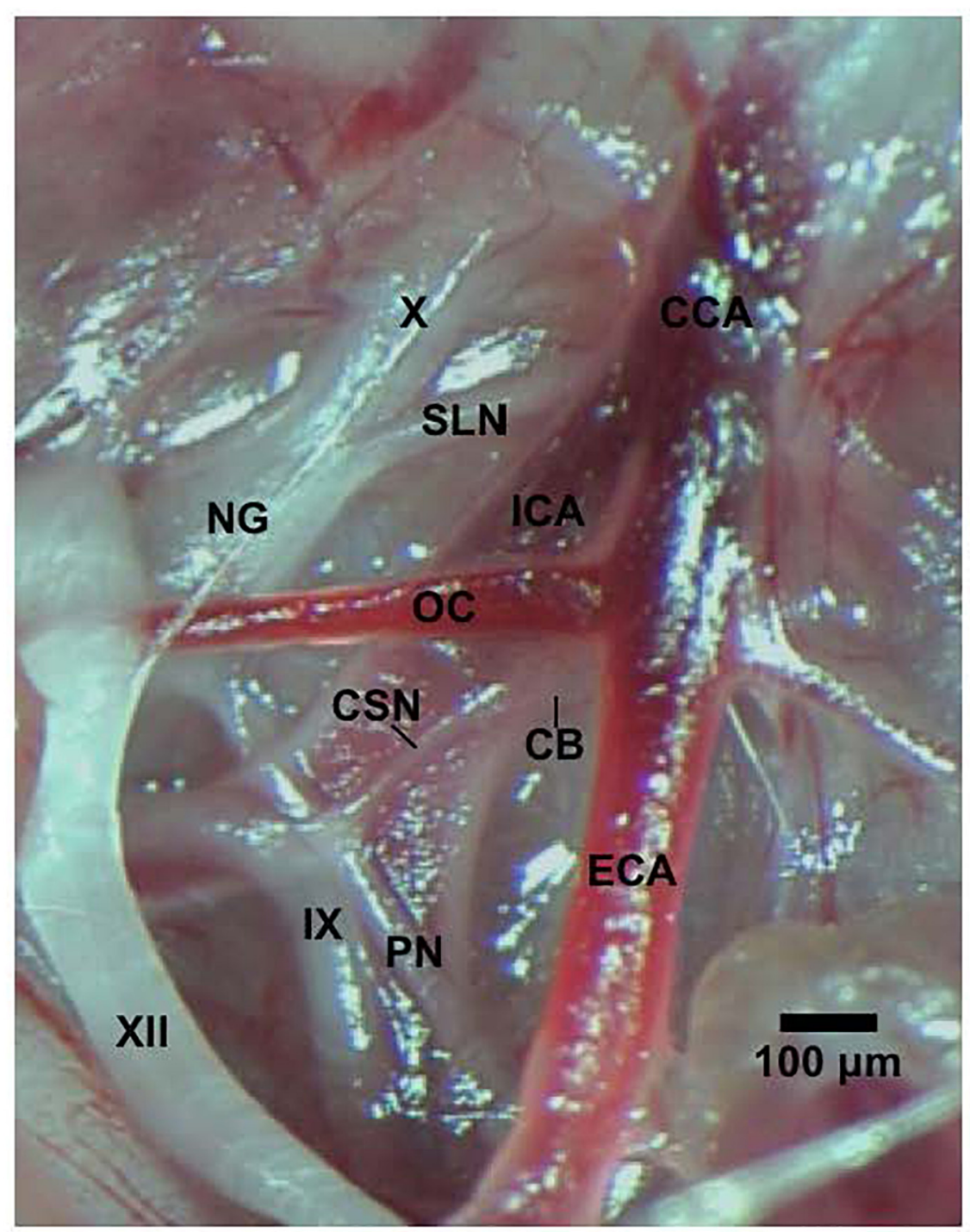

FIGURE 1 | Photograph in a SD male P25 juvenile rat of the carotid sinus nerve (CSN) branching off the glossopharyngeal nerve (IX) and entering the carotid body (CB). The pharyngeal nerve (PN), hypoglossal nerve (XII), nodose ganglion (NG), vagus nerve (X), superior laryngeal nerve (SLN), common carotid artery (CCA), internal (ICA), and external (ECA) carotid arteries, and occipital artery (OC) are also shown. This dissection was done on the left side of the animal. The scale bar is $100 \mu \mathrm{m}$.

stable baseline values to be recorded over a 15 min period prior to exposing the rats to $\mathrm{HX}, \mathrm{HC}$ and $\mathrm{HH}$ gas challenges. After the rats where placed in their chamber, they would explore the new environment for about 15-20 min after which time they would usually lay still, periodically grooming themselves and occasionally sniffing. As such, at the time the HX, HC and $\mathrm{HH}$ gases were delivered to the chambers, the rats were awake and resting quietly. The behavior of the rats did not change appreciably upon delivery of the $\mathrm{HX}, \mathrm{HC}$ and $\mathrm{HH}$ gas challenges. The occasional rat explored for 15-30 s or groomed for 5-10 s. The rats actually underwent five 5-min episodes of a poikilocapnic $\mathrm{HX}\left(10 \% \mathrm{O}_{2}, 90 \% \mathrm{~N}_{2}\right), \mathrm{HC}\left(5 \% \mathrm{CO}_{2}, 21 \% \mathrm{O}_{2}\right.$, $\left.74 \% \mathrm{~N}_{2}\right)$ or $\mathrm{HH}\left(5 \% \mathrm{CO}_{2}, 10 \% \mathrm{O}_{2}, 85 \% \mathrm{~N}_{2}\right)$ gas challenge each separated by $15 \mathrm{~min}$ of room-air. We referred to this as the $5 \times 5$
$\mathrm{HX}, \mathrm{HC}$ or $\mathrm{HH}$ gas challenge, however, this manuscript will detail the responses that occurred during the first gas challenge only, with findings pertaining to responses that occurred during challenges 2-5 to be detailed in subsequent reports. As such, we designated the responses elicited by the first gas challenge as episode 1 (E1) in this manuscript. The data was continuously recorded before, during the entire $5 \times 5 \mathrm{HX}, \mathrm{HC}$ or $\mathrm{HH}$ gas challenge, and during the 15 min post-challenge periods. For each ventilatory parameter, data points collected during every $15 \mathrm{~s}$ epoch were averaged for each rat for graphing and analyses. The maximal values during the $\mathrm{HX}, \mathrm{HC}$ or $\mathrm{HH}$ gas challenge did not necessarily occur during the same $15 \mathrm{~s}$ epoch in each rat, and so the maximal values obtained by each rat was also collected. Moreover, the maximal attainable values that occurred 
throughout the entire study (whether during the $5 \times 5 \mathrm{HX}, \mathrm{HC}$ or $\mathrm{HH}$ gas challenge or subsequent RA phases) were determined. Every $15 \mathrm{~s}$ value was sorted from largest to smallest and the top ten highest values were averaged to provide the maximal attainable $\mathrm{fR}, \mathrm{VT}$, and MV values.

\section{Data Analysis}

All values are expressed as mean \pm SEM. The data were analyzed by one-way or two-way analysis of variance tests that were followed by Student's modified $t$-tests with Bonferroni corrections for multiple comparisons between means using the error mean square terms arising from the ANOVA tests (Wallenstein et al., 1980) as detailed previously (May et al., 2013a,b). The ANOVAs and the multiple comparisons tests were performed using the statistical programs, JMP Statistical Analysis Software (JMP, Cary, NC, United States) and Sigma XL (SigmaStat, Canada, Kitchener, ON, Canada). In every instance, these programs tested for normality and homogeneity of variances before running the ANOVAs. All data sets were normally distributed with homogenous variances and therefore suitable for ANOVA testing. For each rat, the Pre-values for each parameter were determined as the average of the values recorded over the 90 s (i.e., six 15-s epochs) immediately prior to each gas challenge. These resting (baseline) data, and the data recorded over the entire acclimatization period, from the six groups of rats (SHAM and CSNX groups for the $\mathrm{HX}, \mathrm{HC}$ and $\mathrm{HH}$ gas challenges) were analyzed by one-way ANOVA with Bonferroni corrections. The arithmetic changes in ventilatory parameters elicited by the gas challenges at 15 , 30,45 , and $60 \mathrm{~s}$ were determined by simply subtracting the actual values obtained at these time points for each rat from the Pre-value recorded for each rat. Group data for SHAM or CSNX groups (12 values, 4 times $\times 3$ gas challenges per group) were analyzed by two-way ANOVA with Bonferroni corrections. These individual values were summed to provide the total of these responses. The resulting three values for each SHAM and CSNX groups (HX, $\mathrm{HC}$ and $\mathrm{HH}$ values) were then analyzed by one-way ANOVA with Bonferroni corrections. The total arithmetic changes in ventilatory parameters in SHAM and CSNX rats were calculated from Pre-values and summed to provide the total response (i.e., sum of 20 individual $15 \mathrm{~s}$ epochs for the $5 \mathrm{~min}$ challenge). The resulting three values for each of the SHAM and CSNX groups ( $\mathrm{HX}, \mathrm{HC}$ and $\mathrm{HH}$ values) were then analyzed by one-way ANOVA with Bonferroni corrections. To compare the ventilatory parameters recorded during the actual $\mathrm{HH}$ challenge with the additive $\mathrm{HX}+\mathrm{HC}$ values, we performed simple addition of responses obtained from the rats that received the HX challenge and from rats that received the $\mathrm{HC}$ challenge. These data are presented as mean of summed values \pm SEM (10\% of mean). The $10 \%$ SEM value was chosen because it is consistent with the SEM values of the actual data. It is important to note that none of the theoretical $\mathrm{HX}+\mathrm{HC}$ values were used in any of the statistical analyses as the $\mathrm{HX}+\mathrm{HC}$ values were only shown to support the interpretation of the actual $\mathrm{HX}, \mathrm{HC}$ and $\mathrm{HH}$ responses. For descriptive purpose only, we chose a percentage difference of greater or less than $25 \%$ of the actual $\mathrm{HH}$ values to be a noticeable change from the $\mathrm{HX}+\mathrm{HC}$ values and therefore subject to discussion.

\section{RESULTS}

\section{Resting Parameters}

A summary of the descriptors and baseline ventilatory parameters for SHAM and CSNX rats is provided in Table 1. The ages and body weights of the SHAM and CSNX groups for the $\mathrm{HX}, \mathrm{HC}$ and $\mathrm{HH}$ gas challenges were statistically similar to one another (upper rows of Table 1). As such, no corrections for differences in body weights were applied to the ventilatory data. The ventilatory parameters shown in the middle rows of Table $\mathbf{1}$ are those recorded throughout the 15-min baseline period, and show that $\mathrm{fR}, \mathrm{VT}$ and $\mathrm{MV}$, in each CSNX group for the HX (poikilocapnic), HC and $\mathrm{HH}$ gas challenge were significantly smaller compared to those in the respective SHAM group $(P<0.05$, CSNX versus SHAM in $\mathrm{HX}, \mathrm{HC}$ and $\mathrm{HH}$ for all comparisons). The ventilatory values in the bottom rows of Table 1 represent those recorded immediately (2-3 $\mathrm{min}$ ) before each $\mathrm{HX}, \mathrm{HC}$ and $\mathrm{HH}$ gas challenge in SHAM and CSNX groups (i.e., Prevalues). Pre-values were significantly depressed for fR, VT, and $\mathrm{MV}$ in each CSNX group (i.e., each CSNX group for $\mathrm{HX}, \mathrm{HC}$, and $\mathrm{HH}$ gas challenge) compared to the respective SHAM group.

\section{Example Traces Recorded at Baseline and During HX, HC, or HH Gas Challenges}

Representative sections of plethysmography traces from SHAM and CSNX rats are shown in Figure 2. In response to $\mathrm{HX}$, the $\mathrm{fR}$ in the SHAM rat increased from 102 to 144 breaths/min $(+42$ breaths/min). The increase in $\mathrm{fR}$ in the CSNX rat was smaller (from 102 to 108 breaths/min, +6 breaths/min). In response to $\mathrm{HC}, \mathrm{fR}$ in the SHAM rat increased from 96 to 144 breaths/min ( +48 breaths/min). The increase in $\mathrm{fR}$ in the CSNX rat was similar (from 108 to 162 breaths/min, +54 breaths/min). In response to $\mathrm{HH}, \mathrm{fR}$ in the SHAM rat increased from 102 to 186 breaths $/ \mathrm{min}$ $(+84$ breaths $/ \mathrm{min})$. The increase in $\mathrm{fR}$ in the CSNX rat was smaller (from 102 to 138 breaths/min, +36 breaths/min). The increase in $\mathrm{fR}$ to $\mathrm{HH}$ in the SHAM rat $(+84$ breaths/min) was similar to simple addition of the HX and $\mathrm{HC}$ responses $(42+48=90$ breaths $/ \mathrm{min})$, whereas the $\mathrm{HH}$ response in the CSNX rat $(+36$ breaths/min) was much smaller than the simple addition of the $\mathrm{HX}$ and $\mathrm{HC}$ responses $(6+$ $54=60$ breaths $/ \mathrm{min})$.

\section{Comparison of the HX-, HC-, and $\mathrm{HH}$-Induced Responses to the Maximal Attainable Values}

The detailed changes in ventilatory responses to $\mathrm{HX}, \mathrm{HC}$ and $\mathrm{HH}$ gas challenges will be described below. It is important to note that these challenges, including $\mathrm{HH}$, did not produce 
TABLE 1 | Baseline parameters in sham-operated rats and in those with bilateral transection of the carotid sinus nerve.

\begin{tabular}{|c|c|c|c|c|}
\hline Parameter & Group & HX Challenge & HC Challenge & HH Challenge \\
\hline \multirow[t]{2}{*}{ Number of rats } & SHAM & 14 & 12 & 15 \\
\hline & CSNX & 14 & 12 & 15 \\
\hline \multirow[t]{2}{*}{ Age, days post birth } & SHAM & 25 & 25 & 25 \\
\hline & CSNX & 25 & 25 & 25 \\
\hline \multirow[t]{2}{*}{ Body Weight, grams } & SHAM & $60 \pm 3$ & $68 \pm 3$ & $61 \pm 2$ \\
\hline & CSNX & $62 \pm 4$ & $65 \pm 2$ & $59 \pm 2$ \\
\hline \multicolumn{5}{|c|}{ Values recorded throughout the acclimatization period } \\
\hline \multirow[t]{2}{*}{ Frequency, breaths/min } & SHAM & $123 \pm 5$ & $120 \pm 2$ & $125 \pm 3$ \\
\hline & CSNX & $109 \pm 3^{*}$ & $114 \pm 2^{*}$ & $112 \pm 3^{*}$ \\
\hline \multirow[t]{2}{*}{ Tidal Volume, ml } & SHAM & $0.63 \pm 0.02$ & $0.68 \pm 0.02$ & $0.62 \pm 0.01$ \\
\hline & CSNX & $0.55 \pm 0.01^{*}$ & $0.59 \pm 0.01^{\star}$ & $0.56 \pm 0.01^{\star}$ \\
\hline \multirow[t]{2}{*}{ Minute Ventilation, ml/min } & SHAM & $72 \pm 4$ & $79 \pm 2$ & $75 \pm 1$ \\
\hline & CSNX & $59 \pm 2^{*}$ & $65 \pm 2^{*}$ & $60 \pm 2^{*}$ \\
\hline \multicolumn{5}{|c|}{ Values recorded over the 90 s prior to the gas challenges (i.e., Pre-values) } \\
\hline \multirow[t]{2}{*}{ Frequency, breaths/min } & SHAM & $113 \pm 4$ & $117 \pm 2$ & $119 \pm 3$ \\
\hline & CSNX & $100 \pm 2^{*}$ & $106 \pm 2^{*}$ & $106 \pm 3^{\star}$ \\
\hline \multirow[t]{2}{*}{ Tidal Volume, ml } & SHAM & $0.60 \pm 0.02$ & $0.66 \pm 0.01$ & $0.60 \pm 0.01$ \\
\hline & CSNX & $0.55 \pm 0.01^{*}$ & $0.58 \pm 0.01^{*}$ & $0.55 \pm 0.01^{\star}$ \\
\hline \multirow[t]{2}{*}{ Minute Ventilation, $\mathrm{ml} / \mathrm{min}$} & SHAM & $69 \pm 3$ & $79 \pm 1$ & $73 \pm 2$ \\
\hline & CSNX & $56 \pm 2^{\star}$ & $63 \pm 1^{\star}$ & $59 \pm 2^{*}$ \\
\hline
\end{tabular}

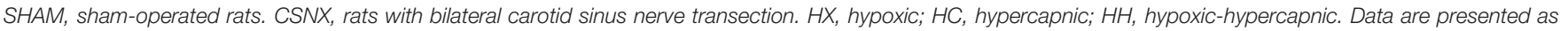
mean \pm SEM. ${ }^{*} P<0.05$, CSNX versus SHAM.

TABLE 2 | Maximal attainable values and maximal values recorded during the gas challenges.

\begin{tabular}{|c|c|c|c|c|c|c|c|}
\hline Parameter & Gas & Group & Pre-value & Maximum & Gas challenge & Maximum delta & Gas challenge delta \\
\hline \multirow[t]{6}{*}{ fR (bpm) } & $H X$ & SHAM & $113 \pm 4$ & $355 \pm 16$ & $193 \pm 10$ & $+242 \pm 16^{\dagger}$ & $+80 \pm 9^{\dagger, \ddagger}$ \\
\hline & & CSNX & $100 \pm 2^{\star}$ & $387 \pm 9$ & $164 \pm 8$ & $+287 \pm 10^{\dagger}$ & $+64 \pm 8^{\dagger, \ddagger}$ \\
\hline & $\mathrm{HC}$ & SHAM & $117 \pm 2$ & $351 \pm 15$ & $222 \pm 18$ & $+234 \pm 17^{\dagger}$ & $+105 \pm 18^{\dagger, \ddagger}$ \\
\hline & & CSNX & $106 \pm 2^{\star}$ & $363 \pm 15$ & $190 \pm 13$ & $+257 \pm 16^{\dagger}$ & $+84 \pm 14^{\dagger, \ddagger}$ \\
\hline & $\mathrm{HH}$ & SHAM & $119 \pm 3$ & $343 \pm 19$ & $246 \pm 11$ & $+224 \pm 19^{\dagger}$ & $+126 \pm 10^{\dagger, \ddagger}$ \\
\hline & & CSNX & $106 \pm 3^{\star}$ & $377 \pm 14$ & $211 \pm 16$ & $+271 \pm 14^{\dagger}$ & $+105 \pm 15^{\dagger, \ddagger}$ \\
\hline \multirow[t]{6}{*}{$\mathrm{VT}(\mathrm{ml})$} & $H X$ & SHAM & $0.60 \pm 0.02$ & $1.12 \pm 0.05$ & $0.97 \pm 0.04$ & $+0.53 \pm 0.04^{\dagger}$ & $+0.37 \pm 0.03^{\dagger, \ddagger}$ \\
\hline & & CSNX & $0.55 \pm 0.01^{*}$ & $1.09 \pm 0.05$ & $0.82 \pm 0.03$ & $+0.54 \pm 0.05^{\dagger}$ & $+0.27 \pm 0.03^{\dagger, \ddagger}$ \\
\hline & $\mathrm{HC}$ & SHAM & $0.66 \pm 0.01$ & $1.14 \pm 0.04$ & $1.03 \pm 0.04$ & $+0.48 \pm 0.03^{\dagger}$ & $+0.37 \pm 0.03^{\dagger, \ddagger}$ \\
\hline & & CSNX & $0.58 \pm 0.01^{\star}$ & $1.00 \pm 0.02$ & $0.88 \pm 0.03$ & $+0.42 \pm 0.02^{\dagger}$ & $+0.30 \pm 0.02^{\dagger, \ddagger}$ \\
\hline & $\mathrm{HH}$ & SHAM & $0.60 \pm 0.01$ & $1.35 \pm 0.04$ & $1.22 \pm 0.04$ & $+0.74 \pm 0.04^{\dagger}$ & $+0.62 \pm 0.03^{\dagger, \ddagger}$ \\
\hline & & CSNX & $0.55 \pm 0.01^{\star}$ & $1.00 \pm 0.03$ & $0.87 \pm 0.02$ & $0.45 \pm 0.03^{\dagger}$ & $+0.32 \pm 0.02^{\dagger, \ddagger}$ \\
\hline \multirow[t]{6}{*}{$\mathrm{MV}$ (ml/min) } & $H X$ & SHAM & $69 \pm 3$ & $222 \pm 13$ & $154 \pm 6$ & $+153 \pm 11^{\dagger}$ & $+84 \pm 5^{\dagger, \ddagger}$ \\
\hline & & CSNX & $56 \pm 2^{*}$ & $234 \pm 13$ & $103 \pm 5$ & $+178 \pm 12^{\dagger}$ & $+46 \pm 5^{\dagger, \ddagger}$ \\
\hline & $\mathrm{HC}$ & SHAM & $79 \pm 1$ & $238 \pm 12$ & $178 \pm 14$ & $+159 \pm 11^{\dagger}$ & $+99 \pm 13^{\dagger, \ddagger}$ \\
\hline & & CSNX & $63 \pm 1^{*}$ & $203 \pm 13$ & $133 \pm 6$ & $+140 \pm 13^{\dagger}$ & $+70 \pm 5^{\dagger, \ddagger}$ \\
\hline & $\mathrm{HH}$ & SHAM & $73 \pm 1$ & $262 \pm 5$ & $240 \pm 4$ & $+190 \pm 6^{\dagger}$ & $+168 \pm 4^{\dagger, \ddagger}$ \\
\hline & & CSNX & $59 \pm 2^{\star}$ & $198 \pm 6$ & $145 \pm 7$ & $+138 \pm 6^{\dagger}$ & $+85 \pm 6^{\dagger, \ddagger}$ \\
\hline
\end{tabular}

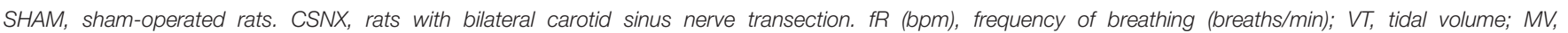

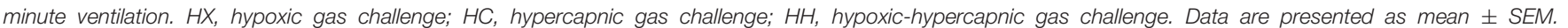

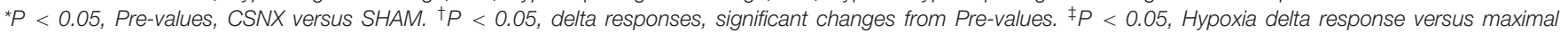
attainable delta response.

changes in ventilatory parameters that approached the maximal attainable responses recorded in these rats throughout the entire study. Specifically, the Pre-values, the maximal values recorded during the entire study (maximum), and the peak values obtained during the HX, $\mathrm{HC}$ or $\mathrm{HH}$ are shown in Table 2. For fR (top rows), VT (middle rows), and MV (bottom rows), the delta values for the gas challenge responses were all smaller than the delta values for the maximal attainable responses in the CSNX group compared to the SHAM $(P<0.05$, for all comparisons). 


\section{SHAM rats}

Baseline

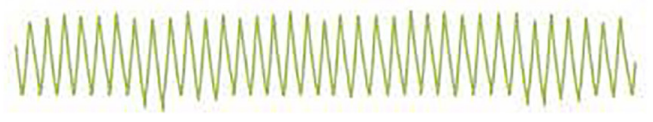

Baseline

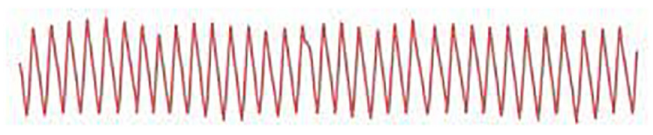

Baseline

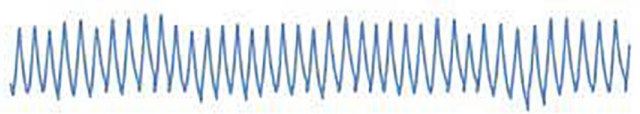

Hypoxia (HX)

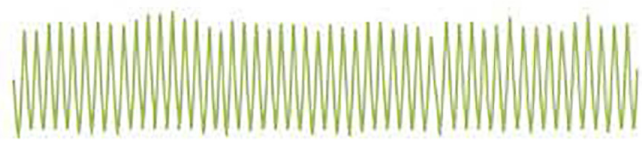

Hypercapnia (HC)

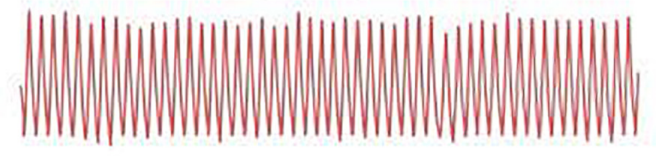

Hypoxia-Hypercapnia (HH)

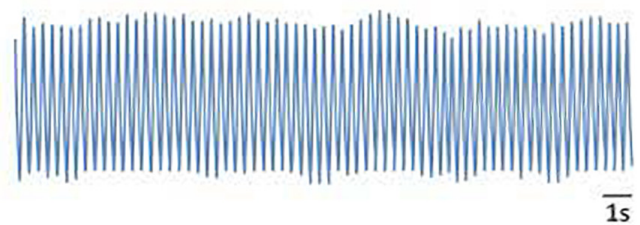

\section{CSNX rats}

Baseline

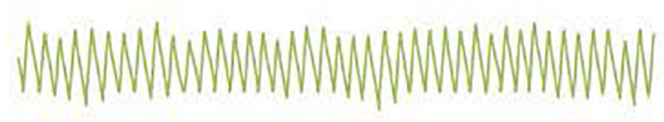

Baseline

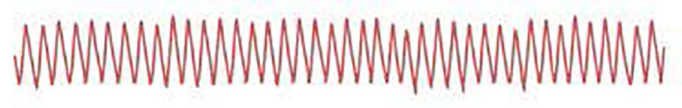

Baseline

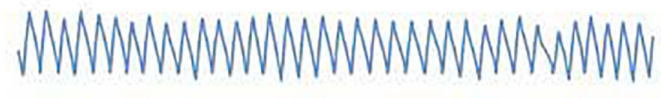

Hypoxia (HX)

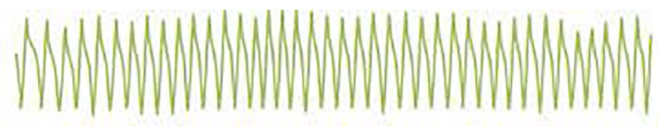

Hypercapnia (HC)

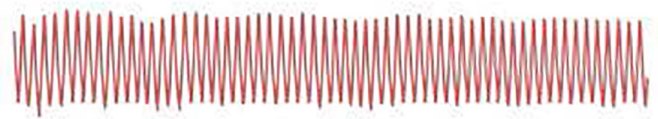

Hypoxia-Hypercapnia (HH)

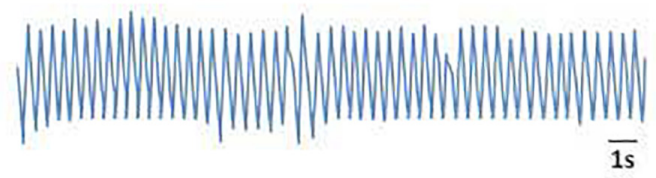

FIGURE 2 | Representative plethysmography traces from sham-operated (SHAM) P25 rats (Top panel) and bilateral carotid sinus nerve transection (CSNX) (Bottom panel) P25 rats recorded at baseline and hypoxic $\left(\mathrm{HX} ; 10 \% \mathrm{O}_{2}, 90 \% \mathrm{~N}_{2}\right)$, hypercapnic $\left(\mathrm{HC} ; 5 \% \mathrm{CO}_{2}, 21 \% \mathrm{O}_{2}, 74 \% \mathrm{~N}_{2}\right)$, or hypoxic-hypercapnic $(\mathrm{HH} ; 5 \% \mathrm{CO}$, $10 \% \mathrm{O}_{2}, 85 \% \mathrm{~N}_{2}$ ) gas challenges.

\section{Frequency of Breathing (fR) in SHAM and CSNX Rats During HX, HC or HH Gas Challenges}

The top panels of Figure 3 summarize fR values of SHAM and CSNX rats before, during, and after exposure to a $5 \mathrm{~min}$ HX, HC or HH gas challenge. In SHAM rats (upper left panel), HX and
HC elicited robust increases in fR that appeared to display rolloff toward the end of the challenge. HH in SHAM rats elicited a robust increase in $\mathrm{fR}$ that did not display roll-off. In CSNX rats (upper right panel), HX elicited an increase in fR that was subject to a more pronounced roll-off than in SHAM rats. The increase in fR elicited by HC in CSNX rats looked comparable to that in SHAM rats, whereas the increase in $\mathrm{fR}$ elicited by $\mathrm{HH}$ challenge 


\section{SHAM rats}
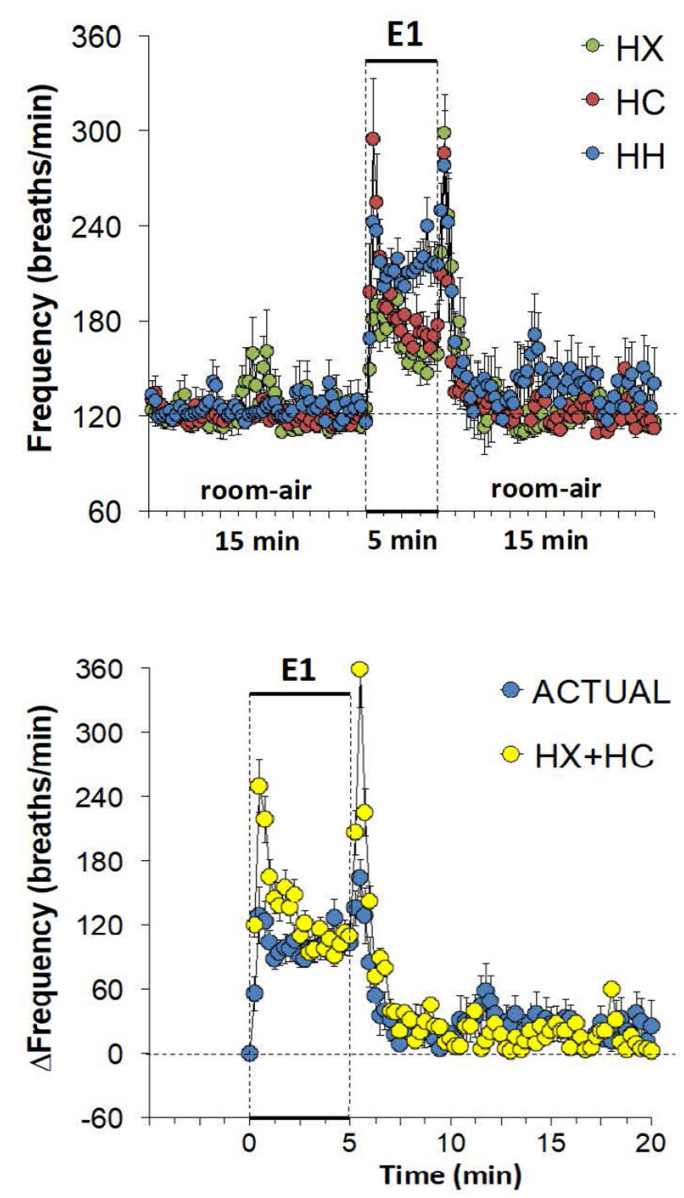

CSNX rats
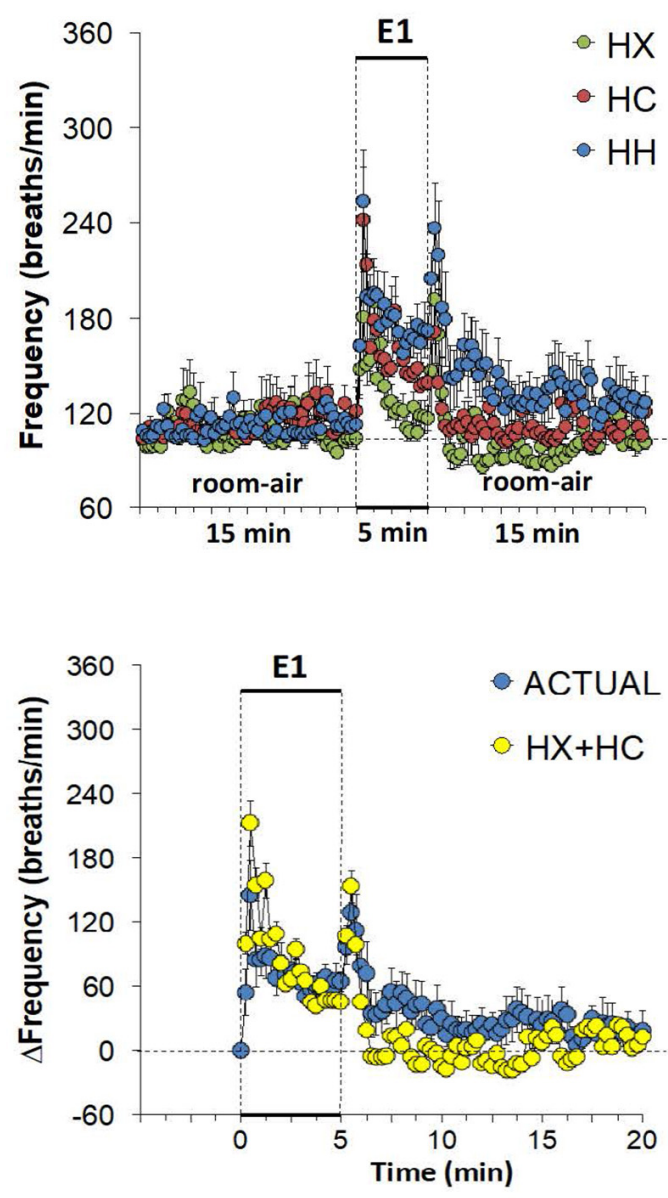

FIGURE 3 | Top panels: Frequency of breathing (fR) values averaged every $15 \mathrm{~s}$ in freely moving sham-operated (SHAM) rats and in rats with bilateral carotid sinus nerve transection (CSNX) during exposure to a single episode (E1) of hypoxic $\left(\mathrm{HX} ; 10 \% \mathrm{O}_{2}, 90 \% \mathrm{~N}_{2}\right)$, hypercapnic ( $\left.\mathrm{HC} ; 5 \% \mathrm{CO}_{2}, 21 \% \mathrm{O}_{2}, 74 \% \mathrm{~N}_{2}\right)$, or hypoxic-hypercapnic $\left(\mathrm{HH} ; 5 \% \mathrm{CO}_{2}, 10 \% \mathrm{O}_{2}, 85 \% \mathrm{~N}_{2}\right)$ gas challenge of 5 min in duration, followed by 15 min of room-air. The data are presented as mean \pm SEM. Bottom panels: Changes in $\mathrm{FR}$ in SHAM and CSNX rats during the actual $\mathrm{HH}$ gas challenge compared to addition of $\mathrm{HX}+\mathrm{HC}$ values. For the actual $\mathrm{HH}$ values, data are presented as mean \pm SEM and for the $\mathrm{HX}+\mathrm{HC}$ values, data are presented as the mean \pm SEM (10\% of mean).

looked substantially smaller in CSNX rats than SHAM rats. The bottom panels of Figure 3 summarize the arithmetic changes in $\mathrm{fR}$ that occurred throughout the actual $\mathrm{HH}$ protocol, and simple addition of $\mathrm{HX}$ and $\mathrm{HC}$ values (HX+HC, SEM values presented as $10 \%$ of the mean to provide perspective). The actual $\mathrm{HH}$ values in SHAM rats (bottom left panel) were smaller than the $\mathrm{HX}+\mathrm{HC}$ values during the initial phases of the $\mathrm{HH}$ gas challenge compared to $\mathrm{HX}+\mathrm{HC}$, and the initial seconds upon return to room-air. In SHAM rats, the maximal attainable changes in $\mathrm{fR}$ during the entire $\mathrm{HH}$ protocol was $+224 \pm 19$ breaths $/ \mathrm{min}$ (Table 2), which was much higher than the changes in the $\mathrm{HH}$ gas challenge $(+126 \pm 10$ breaths $/ \mathrm{min})$ (Table 2$)$. In SHAM rats, the summed changes in $\mathrm{HX}$ and $\mathrm{HC}$ responses $(+80 \pm 9$ and $+105 \pm 18$ breaths/min, respectively; +185 breaths/min upon addition) was smaller than the maximal attainable changes in $\mathrm{fR}$ during the entire $\mathrm{HH}$ protocol $(+224 \pm 19$ breaths/min). In contrast to SHAM rats, the $\mathrm{HH}$ and $\mathrm{HX}+\mathrm{HC}$ responses in
CSNX rats (bottom right panel) were similar to one another. For CSNX rats, the maximal attainable changes in $\mathrm{fR}$ during the entire $\mathrm{HH}$ protocol $(+271 \pm 14$ breaths/min) (Table 2), was again substantially higher than those observed during the $\mathrm{HH}$ gas challenge $(+105 \pm 15$ breaths/min) or those obtained by summation of the HX and $\mathrm{HC}$ responses $(+64 \pm 9$ and $+84 \pm 14$ breaths/min, respectively; +148 breaths/min upon addition).

The top panels of Figure 4 compare the total increases in $\mathrm{fR}$ that occurred during the single $\mathrm{HX}, \mathrm{HC}$ or $\mathrm{HH}$ gas challenge in SHAM and CSNX rats. All three challenges elicited substantial increases in $\mathrm{fR}$ from Pre-values. The increase in $\mathrm{fR}$ elicited by HX was smaller in CSNX rats than in SHAM rats. The increase in $\mathrm{fR}$ during $\mathrm{HC}$ were not statistically smaller in CSNX rats compared to SHAM rats. The increase in $\mathrm{fR}$ during $\mathrm{HH}$ in CSNX rats was smaller than in SHAM rats. Table 3 shows the arithmetic differences between the total $5 \mathrm{~min} \mathrm{HX}, \mathrm{HC}$ and $\mathrm{HH}$ fR responses in SHAM and CSNX rats, with the (-) negative values 


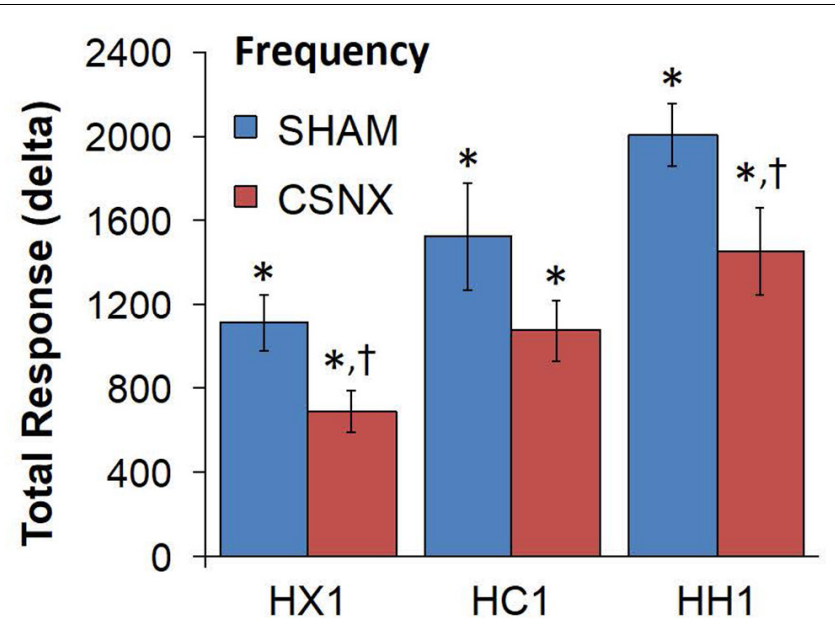

SHAM rats

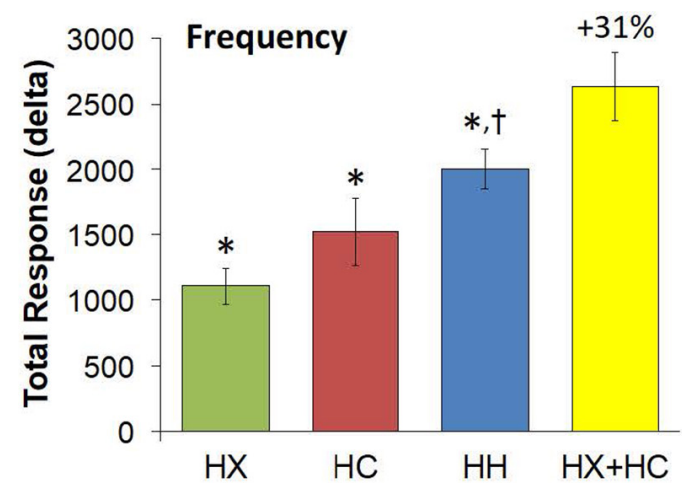

CSNX rats

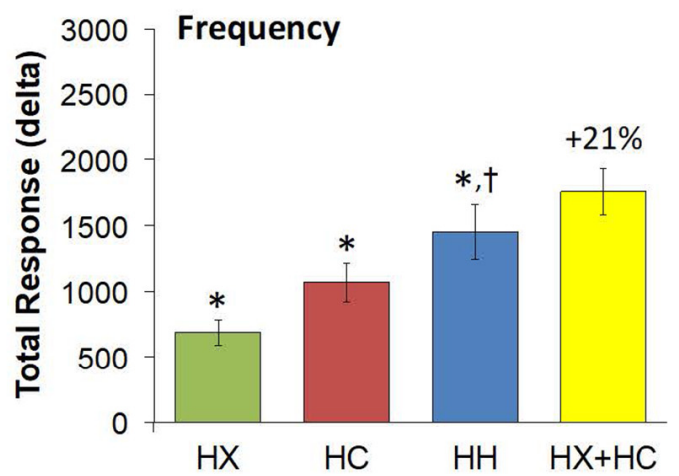

FIGURE 4 | Top panels: Total arithmetic changes in frequency of breathing (fR) that occurred during exposure to a single hypoxic $\left(H X 1,10 \% \mathrm{O}_{2}, 90 \% \mathrm{~N}_{2}\right)$, hypercapnic $\left(\mathrm{HC1}, 5 \% \mathrm{CO}_{2}, 21 \% \mathrm{O}_{2}, 74 \% \mathrm{~N}_{2}\right)$ or hypoxic-hypercapnic $\left(\mathrm{HH} 1,5 \% \mathrm{CO}_{2}, 10 \% \mathrm{O}_{2}, 85 \% \mathrm{~N}_{2}\right)$ gas challenge in SHAM and CSNX rats. The data are presented as mean \pm SEM. ${ }^{*} P<0.05$, significant response from Pre-value. ${ }^{\dagger} P<0.05$, CSNX versus SHAM. Bottom panels: Total arithmetic changes in fR values in SHAM (left panel) and CSNX (right panel) rats during exposure to the $\mathrm{HX}, \mathrm{HC}$ or $\mathrm{HH}$ gas challenges. The sum of $\mathrm{HX}$ and $\mathrm{HC}$ values $(\mathrm{HX}+\mathrm{HC})$ expressed as mean \pm SEM (10\% of mean) are shown. The figures in parentheses above the $\mathrm{HX}+\mathrm{HC}$ columns are the percentage (\%) differences between actual $\mathrm{HH}$ values and $\mathrm{HX}+\mathrm{HC}$ values. ${ }^{*} P<0.05$, significant response from Pre-value. ${ }^{\dagger} P<0.05, \mathrm{HH}$ versus $\mathrm{HX}$.

meaning that the responses in CSNX rats were smaller than in SHAM rats. The differences in responses of CSNX and SHAM rats for the additive $\mathrm{HX}+\mathrm{HC}$ values are also shown. The actual $\mathrm{fR}$ differences in $\mathrm{HH}$ responses between SHAM and CSNX rats were far smaller than predicted by the addition of $\mathrm{HX}$ and $\mathrm{HC}$ $(\mathrm{HX}+\mathrm{HC})$ responses. The bottom panels of Figure 4 summarize the total $\mathrm{fR}$ responses elicited by $\mathrm{HX}, \mathrm{HC}$ and $\mathrm{HH}$ in SHAM rats (bottom left panel) and CSNX rats (bottom right panel). The $\mathrm{HX}+\mathrm{HC}$ values are also shown, with the values above the columns noting the percentage difference between the actual $\mathrm{HH}$ values and $\mathrm{HX}+\mathrm{HC}$ values. In SHAM rats, the $\mathrm{R}$ response elicited by the actual $\mathrm{HH}$ gas challenge was smaller than the summed $\mathrm{HX}+\mathrm{HC}$ values. In the CSNX rats, the $\mathrm{fR}$ response elicited by the actual $\mathrm{HH}$ gas challenge was similar to the summed $\mathrm{HX}+\mathrm{HC}$ values, suggesting that $\mathrm{fR}$ is less than additive in SHAM rats and mostly additive in CSNX rats.

Rapid responses to $\mathrm{HX}, \mathrm{HC}$ and $\mathrm{HH}$ would be expected to involve $\mathrm{CB}$ chemoafferents. As such, we focused on the $\mathrm{fR}$ responses that occurred during the first $60 \mathrm{~s}$ of the $\mathrm{HX}, \mathrm{HC}$ and $\mathrm{HH}$ gas challenge in SHAM and CSNX rats. The changes in $\mathrm{R}$ that occurred during the first $60 \mathrm{~s}$ of the $\mathrm{HX}, \mathrm{HC}$ and $\mathrm{HH}$ gas challenges are shown in the top panels of Figure 5. For SHAM rats (top left panel), the initial increases in $\mathrm{fR}$ elicited by $\mathrm{HX}$ were less than those elicited by the $\mathrm{HC}$ or $\mathrm{HH}$, whereas there were minimal differences between $\mathrm{HX}, \mathrm{HC}$ and $\mathrm{HH}$ responses in CSNX rats (top right panel). Overall, the responses during 
the first $60 \mathrm{~s}$ of HX, HC and $\mathrm{HH}$ were similar in SHAM and CSNX rats. Next, we wanted to determine whether the changes in magnitude of the actual $\mathrm{fR}$ response during the first $60 \mathrm{~s}$ of the $\mathrm{HH}$ gas challenge was simply additive of those elicited by the HX and $\mathrm{HC}$ alone. As seen in the middle panels of Figure 5, the actual $\mathrm{HH}$ values in SHAM rats (middle left panel) were substantially less than those of the summed $\mathrm{HX}+\mathrm{HC}$ values. The actual $\mathrm{HH}$ values in CSNX rats (middle right panel) were somewhat less than those of the added $\mathrm{HX}+\mathrm{HC}$ values. The bottom panels of Figure 5 show the total $\mathrm{fR}$ responses that occurred during the first $60 \mathrm{~s}$ of $\mathrm{HX}$, $\mathrm{HC}$, and $\mathrm{HH}$ gas challenges in SHAM and CSNX rats. Again, for SHAM rats (bottom left panel), the increase in $\mathrm{fR}$ during the first $60 \mathrm{~s}$ elicited by $\mathrm{HH}$ was less than would be expected by simple addition of the HX and $\mathrm{HC}$ responses. This was also true for CSNX rats (bottom right panel). The clear impression given by the data is that there is a negative interaction between HX and $\mathrm{HC}$ signaling pathways during the first $60 \mathrm{~s}$ of a $\mathrm{HH}$ gas challenge, and this interaction is independent of the presence or absence of the CB-CSN complex.

\section{Tidal Volume (VT) in SHAM and CSNX Rats During HX, HC or HH Gas Challenges}

The top panels of Figure 6 summarize the VT values recorded in SHAM and CSNX rats before, during, and after exposure to $5 \mathrm{~min}$ $\mathrm{HX}, \mathrm{HC}$ or $\mathrm{HH}$ gas challenge. In SHAM rats (top left panel), $\mathrm{HX}$ and $\mathrm{HC}$ gas challenges elicited robust and sustained increases in VT that were similar to one another. HH gas challenge also elicited a sustained increase in VT that appeared greater than those elicited by $\mathrm{HX}$ or HC. In contrast, the increases in VT elicited by $\mathrm{HX}, \mathrm{HC}$ and $\mathrm{HH}$ gas challenges in CSNX rats (top right panel) were similar to one another, and all smaller than those in SHAM rats. The bottom panels of Figure 6 summarize the arithmetic changes in VT that occurred throughout the actual $\mathrm{HH}$ gas challenge and the simple addition of $\mathrm{HX}$ and $\mathrm{HC}$ values $(\mathrm{HX}+\mathrm{HC})$. In SHAM rats (bottom left panel), the actual $\mathrm{HH}$ values and additive $\mathrm{HX}+\mathrm{HC}$ values were remarkably similar to one another. The maximal attainable changes in VT in the SHAM rat during the entire $\mathrm{HH}$ protocol, was $+0.74 \pm 0.04 \mathrm{ml}$ (Table 2), which was higher than the changes during the $\mathrm{HH}$ gas challenge $(+0.62 \pm 0.03 \mathrm{ml})$, but equal to the sum of the HX and HC $(\mathrm{HX}+\mathrm{HC})$ responses $(+0.37 \pm 0.03 \mathrm{ml}$ and $+0.37 \pm 0.03 \mathrm{ml}$, respectively; $+0.74 \mathrm{ml}$ upon addition). In contrast, CSNX rats (bottom right panel), the actual HH VT values were substantially smaller than the additive $\mathrm{HX}+\mathrm{HC}$ values. The maximal attainable changes in VT in CSNX rats during the entire $\mathrm{HH}$ protocol, was $+0.45 \pm 0.03 \mathrm{ml}$ (Table 2), which was higher than the changes during the $\mathrm{HH}$ gas challenge $(+0.32 \pm 0.02 \mathrm{ml})$, and lower than the sum of $\mathrm{HX}$ and $\mathrm{HC}(\mathrm{HX}+\mathrm{HC})$ responses $(+0.27 \pm 0.03 \mathrm{ml}$ and $+0.30 \pm 0.02 \mathrm{ml}$, respectively; $+0.57 \mathrm{ml}$ upon addition).

The top panel of Figure 7 compares the total increases in VT that occurred during the single $\mathrm{HX}, \mathrm{HC}$ or $\mathrm{HH}$ gas challenge in SHAM and CSNX rats. The total increases in VT elicited by $\mathrm{HX}$ were significantly smaller in CSNX rats than SHAM rats, whereas the VT responses during $\mathrm{HC}$ were similar in both groups. The total increases in VT elicited by $\mathrm{HH}$ were markedly smaller in CSNX rats than in SHAM rats. As shown in Table 3, the arithmetic differences in VT between SHAM and CSNX rats for $\mathrm{HX}$ of $-2.01 \mathrm{ml}$ and for $\mathrm{HC}$ of $-0.43 \mathrm{ml}$ would add to $-2.44 \mathrm{ml}$, whereas the difference for the actual $\mathrm{HH}$ was $-4.65 \mathrm{ml}$, suggesting that the actual VT difference in $\mathrm{HH}$ responses between SHAM and CSNX rats were far greater than predicted by addition of $\mathrm{HX}$ and $\mathrm{HC}(\mathrm{HX}+\mathrm{HC})$ responses. The bottom panels of Figure 7 summarize the total VT responses elicited $\mathrm{HX}, \mathrm{HC}$ and $\mathrm{HH}$ in SHAM rats (bottom left panel) and CSNX rats (bottom right panel). The $\mathrm{HX}+\mathrm{HC}$ values are also shown with figures above the $\mathrm{HX}+\mathrm{HC}$ columns showing the percentage difference between the actual $\mathrm{HH}$ values and the $\mathrm{HX}+\mathrm{HC}$ values. In SHAM rats, the VT responses elicited by $\mathrm{HX}$ and $\mathrm{HC}$ appeared to be additive since the actual $\mathrm{HH}$ values were closely aligned with the computed $\mathrm{HX}+\mathrm{HC}$ values. In contrast, the VT responses between HX and HC changed markedly in CSNX rats, such that the $\mathrm{HX}, \mathrm{HC}$ and $\mathrm{HH}$ responses were similar to one another, and the actual $\mathrm{HH}$ responses were markedly lower than the added $\mathrm{HX}+\mathrm{HC}$ responses. Therefore, the additive effects of $\mathrm{HX}$ and HC signaling pathways were markedly diminished in rats with bilateral CSN transection.

As mentioned, the rapid responses to $\mathrm{HX}, \mathrm{HC}$, and $\mathrm{HH}$ would be expected to involve $\mathrm{CB}$ chemoafferents, and therefore we compared the changes in VT that occurred within the first $60 \mathrm{~s}$ of the HX, HC and $\mathrm{HH}$ gas challenges in SHAM and CSNX rats. The changes in VT that occurred during the first $60 \mathrm{~s}$ of the $\mathrm{HX}, \mathrm{HC}$ and $\mathrm{HH}$ gas challenges are shown in the top panels of Figure 8. For SHAM rats (top left panel), the increases in VT elicited by $\mathrm{HC}$ were smaller than those elicited by $\mathrm{HX}$ or $\mathrm{HH}$. The magnitude of the initial VT responses elicited by HX, HC and $\mathrm{HH}$ in CSNX rats (top right panel) were overall smaller than those in SHAM rats. Unlike the SHAM rats, $\mathrm{HX}, \mathrm{HC}$ and $\mathrm{HH}$ elicited similar initial VT responses in CSNX rats. As seen in the middle panels of Figure 8, the magnitudes of the actual VT responses during the first $60 \mathrm{~s}$ of the $\mathrm{HH}$ gas challenge were, in general, simply additive of those elicited by $\mathrm{HX}$ and $\mathrm{HC}$ alone in both SHAM and CSNX rats, except at the $60 \mathrm{~s}$ time-point. The bottom panels of Figure 8 summarize the total VT responses that occurred during $\mathrm{HX}, \mathrm{HC}$ and $\mathrm{HH}$ in SHAM (bottom left panel) and CSNX (bottom right panel) rats. Again, for SHAM rats, the initial increases in $\mathrm{VT}$ elicited by $\mathrm{HH}$ were about that expected by simple addition of $\mathrm{HX}$ and $\mathrm{HC}$ responses. In contrast, the initial VT responses elicited by $\mathrm{HH}$ in CSNX rats were markedly less than expected from simple addition of HX and $\mathrm{HC}$ responses. Overall, and in contrast to the $\mathrm{fR}$ responses, the VT $60 \mathrm{~s}$ data suggests that there is a positive interaction between $\mathrm{HX}$ and $\mathrm{HC}$ signaling pathways during the first $60 \mathrm{~s}$ of a $\mathrm{HH}$ gas challenge, and that this interaction is dependent on the presence of the CB-CSN complex.

\section{Minute Ventilation (MV) in SHAM and CSNX Rats During HX, HC or HH Gas Challenges}

The top panels of Figure 9 summarize the MV values recorded in SHAM and CSNX rats before, during, and after exposure to a 5 min $\mathrm{HX}, \mathrm{HC}$ or $\mathrm{HH}$ gas challenge. In SHAM rats (top left 
TABLE 3 | Arithmetic differences between the responses observed in sham-operated rats and those with bilateral transection of the carotid sinus nerve.

\begin{tabular}{|c|c|c|c|c|c|c|}
\hline & \multicolumn{2}{|c|}{ Frequency (breaths/min) } & \multicolumn{2}{|c|}{ Tidal volume (ml) } & \multicolumn{2}{|c|}{ Minute ventilation (ml/min) } \\
\hline & Delta ACTUAL & Delta $\mathrm{HX}+\mathrm{HC}$ & Delta ACTUAL & Delta HX+HC & Delta ACTUAL & Delta $\mathrm{HX}+\mathrm{HC}$ \\
\hline $\mathrm{HX} 1$ & -419 & & -2.01 & & -667 & \\
\hline $\mathrm{HC} 1$ & -451 & & -0.43 & & -635 & \\
\hline $\mathrm{HH} 1$ & -554 & -870 & -4.65 & -2.44 & -1448 & -1302 \\
\hline
\end{tabular}

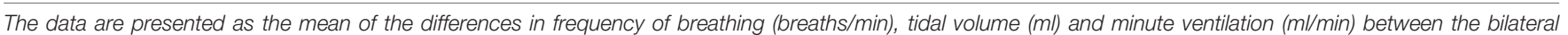
carotid sinus nerve transected rats and the sham-operated rats. HX, hypoxic gas challenge; HC, hypercapnic gas challenge; HH, hypoxic-hypercapnic gas challenge.

panel), the HX and HC challenges elicited robust increases in MV that were relatively similar to one another, except there was a more robust roll-off during HX than HC. The increases in MV during $\mathrm{HH}$ were markedly greater than those during $\mathrm{HX}$ or $\mathrm{HC}$. HX, $\mathrm{HC}$ and $\mathrm{HH}$ also elicited reproducible increases in MV in CSNX rats (top right panel) that appeared substantially smaller than those in SHAM rats. In CSNX rats, the increases in $\mathrm{MV}$ elicited by $\mathrm{HH}$ were similar to those elicited by $\mathrm{HC}$, but greater than those elicited by HX. The bottom panels of Figure 9 summarize the arithmetic changes in MV that occurred during the actual $\mathrm{HH}$ gas challenge and from simple addition of $\mathrm{HX}$ and $\mathrm{HC}$ gas challenge values $(\mathrm{HX}+\mathrm{HC})$. The actual $\mathrm{HH}$ values and additive $\mathrm{HX}+\mathrm{HC}$ values were remarkably similar in SHAM rats (bottom left panel) and CSNX rats (bottom right panel). The maximal attainable changes in MV in SHAM rats during the entire $\mathrm{HH}$ protocol was $+190 \pm 6 \mathrm{ml} / \mathrm{min}$ (Table 2), which was much higher than the changes during the $\mathrm{HH}$ gas challenge $(+168 \pm 4 \mathrm{ml} / \mathrm{min}$ ) (Table 2), but similar to the sum of the HX and $\mathrm{HC}(\mathrm{HX}+\mathrm{HC})$ gas challenge responses $(+84 \pm 5 \mathrm{ml} / \mathrm{min}$ and $+99 \pm 13 \mathrm{ml} / \mathrm{min}$, respectively; $+183 \mathrm{ml} / \mathrm{min}$ upon addition). The maximal attainable changes in MV in CSNX rats during the entire $\mathrm{HH}$ protocol was $+138 \pm 6 \mathrm{ml} / \mathrm{min}$ (Table 2), which was substantially higher than those observed during the $\mathrm{HH}$ gas challenge $(+85 \pm 6 \mathrm{ml} / \mathrm{min})$, and somewhat higher than the sum of the $\mathrm{HX}$ and $\mathrm{HC}(\mathrm{HX}+\mathrm{HC})$ gas challenge responses $(+46 \pm 5 \mathrm{ml} / \mathrm{min}$ and $+70 \pm 5 \mathrm{ml} / \mathrm{min}$, respectively; $+116 \mathrm{ml} / \mathrm{min}$ upon addition).

The top panels of Figure $\mathbf{1 0}$ compare the total increases in $\mathrm{MV}$ that occurred during the single $\mathrm{HX}, \mathrm{HC}$ or $\mathrm{HH}$ gas challenge in SHAM and CSNX rats. The total increases in MV elicited by HX and HC were significantly smaller in CSNX compared to SHAM rats. The total increases in MV elicited by $\mathrm{HH}$ were also significantly smaller in CSNX than SHAM rats. Table 3 shows that the arithmetic differences in MV between SHAM rats and CSNX rats for $\mathrm{HX}$ of $-667 \mathrm{ml} / \mathrm{min}$ and for $\mathrm{HC}$ of $635 \mathrm{ml} / \mathrm{min}$, adds to $-1302 \mathrm{ml} / \mathrm{min}$, and the difference in $\mathrm{MV}$ for the actual $\mathrm{HH}$ gas challenge was $-1448 \mathrm{ml} / \mathrm{min}$, suggesting that the MV difference in $\mathrm{HH}$ responses between SHAM and CSNX rats was similar to that predicted by addition of the HX and $\mathrm{HC}(\mathrm{HX}+\mathrm{HC})$ responses. The bottom panels of Figure 10 summarize the total $\mathrm{MV}$ responses elicited by the $\mathrm{HX}, \mathrm{HC}$ and $\mathrm{HH}$ gas challenges in the SHAM rats (bottom left panel) and CSNX rats (bottom right panel). The summed $\mathrm{HX}+\mathrm{HC}$ values are displayed with figures above the $\mathrm{HX}+\mathrm{HC}$ columns showing the percentage difference between the actual $\mathrm{HH}$ values and $\mathrm{HX}+\mathrm{HC}$ values. It seems evident that the $\mathrm{MV}$ response during $\mathrm{HH}$ was simply equal to the sum of the $\mathrm{HX}$ and $\mathrm{HC}$ $(\mathrm{HX}+\mathrm{HC})$ responses in SHAM rats, whereas in CSNX rats, the summed $\mathrm{HX}+\mathrm{HC}$ responses were slightly greater than the $\mathrm{HH}$ response for $\mathrm{MV}$.

Again, the initial responses to $\mathrm{HX}, \mathrm{HC}$ and $\mathrm{HH}$ would be expected to be mediated by $\mathrm{CB}$ chemoafferents, and so it is important to establish what changes in MV during these challenges occurred within the first $60 \mathrm{~s}$ in SHAM and CSNX rats. The changes in MV that occurred during the first $60 \mathrm{~s}$ of $\mathrm{HX}, \mathrm{HC}$ and $\mathrm{HH}$ are shown in the top panels of Figure 11. In SHAM rats (top left panel), the initial increases in MV elicited by $\mathrm{HX}, \mathrm{HC}$ and $\mathrm{HH}$ were similar to one another. In CSNX rats (top right panel), the initial increases in MV elicited by $\mathrm{HX}, \mathrm{HC}$ and $\mathrm{HH}$ were also similar to one another, and obviously smaller compared to the SHAM rats. Again, we wanted to determine whether the magnitude of the actual $60 \mathrm{~s}$ MV response during $\mathrm{HH}$ was simply additive of that elicited by $\mathrm{HX}$ and $\mathrm{HC}$ alone. As seen in the middle panels of Figure 11, the actual $60 \mathrm{~s}$ MV responses during $\mathrm{HH}$ in both SHAM and CSNX rats were substantially smaller than those of the computed $\mathrm{HX}+\mathrm{HC}$ values. The bottom panels of Figure 11, show the total MV responses that occurred during the first $60 \mathrm{~s}$ of $\mathrm{HX}, \mathrm{HC}$ and $\mathrm{HH}$ in SHAM rats (bottom left panel) and CSNX rats (bottom right panel). The initial increase in $\mathrm{MV}$ elicited by $\mathrm{HH}$ was less than would be expected by simple addition of the HX and HC responses in both SHAM and CSNX rats. Thus, as with (and because of) the fR responses, the concluding message of the $60 \mathrm{~s}$ data is that there is a negative interaction between $\mathrm{HX}$ and $\mathrm{HC}$ signaling pathways during the first $60 \mathrm{~s}$ of the $\mathrm{HH}$ gas challenge, and this is independent of the presence or absence of the CB-CSN complex.

\section{DISCUSSION}

Proper tissue oxygenation is a well-regulated process that is essential for the survival of air-breathing animal species. The $\mathrm{CBs}$ are crucial for detecting changes in arterial $\mathrm{pO}_{2}$, $\mathrm{pCO}_{2}$ and $\mathrm{pH}$. A drop in arterial $\mathrm{pO}_{2}$ (hypoxia) or a rise in $\mathrm{pCO}_{2}$ (hypercapnia) stimulates the $\mathrm{CBs}$, and the sensory information is then relayed to chemoafferents of the CSN, which in turn sends signals to the respiratory control regions in the brainstem to trigger downstream respiratory and cardiovascular reflexes (López-Barneo et al., 2008). Over the years research has shown developmental differences between hypoxia (HX) and hypercapnia (HC) ventilatory responses in neonatal and adult mammals (Bureau et al., 1984; Bonora et al., 1984; McCooke 


\section{SHAM rats}
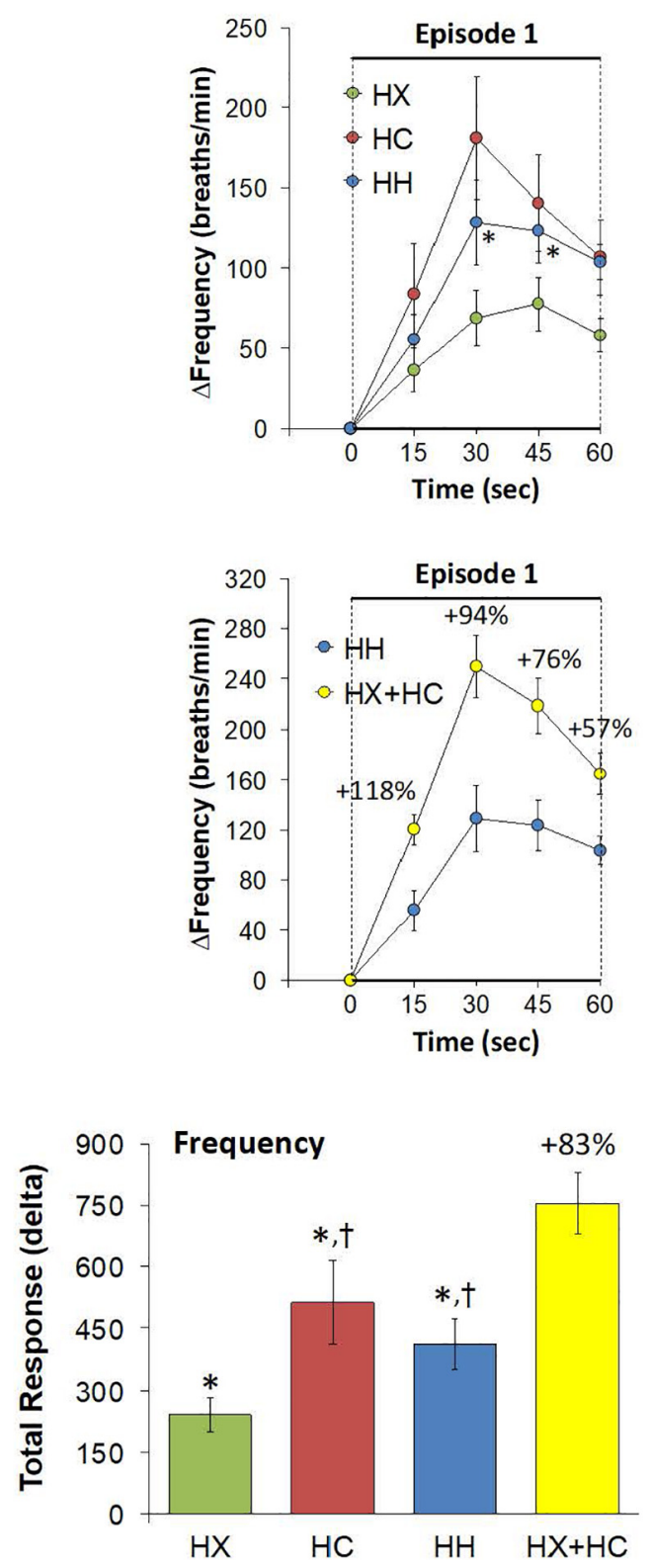

\section{CSNX rats}
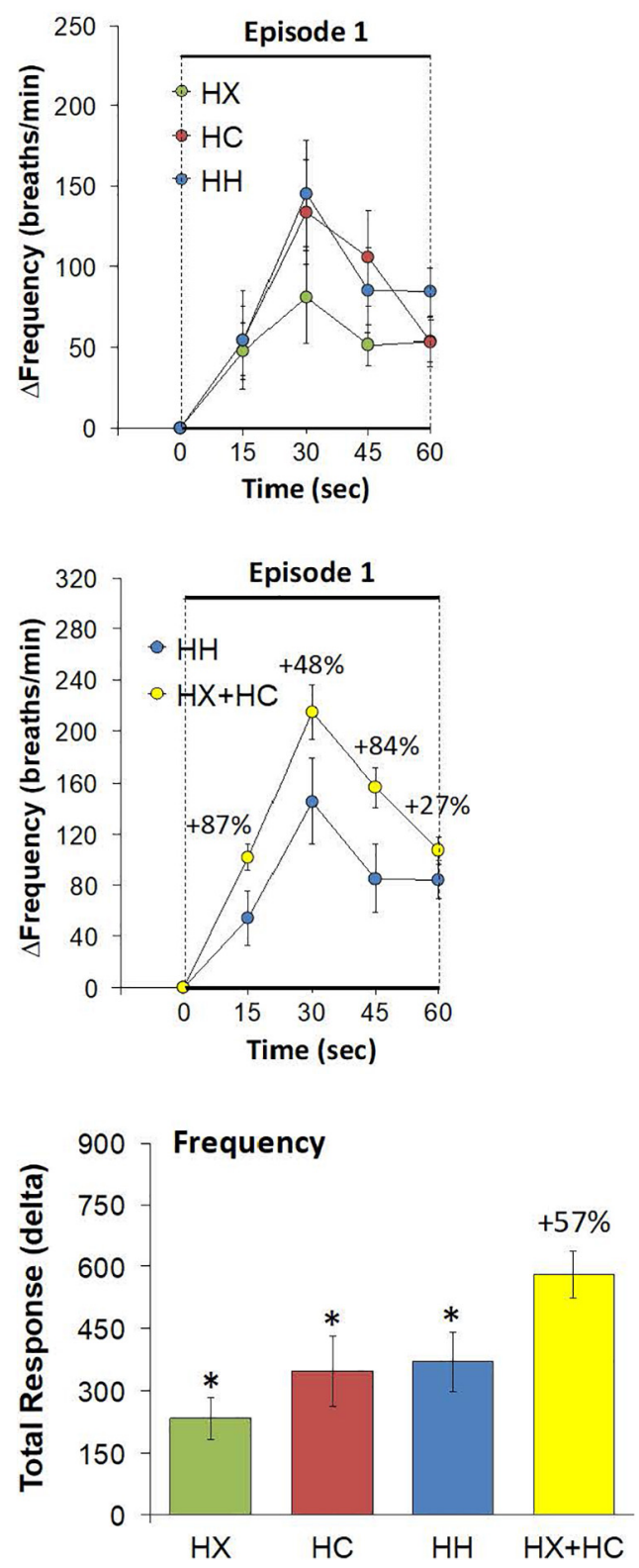

FIGURE 5 | Top panels: Arithmetic changes in frequency of breathing (fR) in freely moving sham-operated (SHAM) rats and in rats with bilateral carotid sinus nerve transection (CSNX) during the first $60 \mathrm{~s}$ of exposure to a single hypoxic $\left(\mathrm{HX}, 10 \% \mathrm{O}_{2}, 90 \% \mathrm{~N}_{2}\right)$, hypercapnic $\left(\mathrm{HC}, 5 \% \mathrm{CO}_{2}, 21 \% \mathrm{O}_{2}, 74 \% \mathrm{~N}_{2}\right)$, or hypoxic-hypercapnic $\left(\mathrm{HH}, 5 \% \mathrm{CO}_{2}, 10 \% \mathrm{O}_{2}, 85 \% \mathrm{~N}_{2}\right)$ gas challenge (Episode 1 (E1)). Data are presented as mean $\pm \mathrm{SEM} .{ }^{*} P<0.05, \mathrm{HH}$ versus $\mathrm{HX}{ }^{\dagger} P<0.05$, $\mathrm{HH}$ versus $\mathrm{HC}$. Middle panels: Arithmetic changes in $\mathrm{fR}$ in SHAM and CSNX rats during the first 60 s of the actual hypoxic-hypercapnic (HH) gas challenge values compared to the addition of the $\mathrm{HX}$ and $\mathrm{HC}(\mathrm{HX}+\mathrm{HC})$ gas challenge values. For the actual $\mathrm{HH}$ values, data are shown as mean $\pm \mathrm{SEM}$ and for $\mathrm{HX}+\mathrm{HC}$ values, data are presented as the mean \pm SEM (10\% of mean). Bottom panels: Total arithmetic changes in fR in SHAM and CSNX rats during the first 60 s of exposure to HX, $\mathrm{HC}$ or $\mathrm{HH}$ gas challenges. The data are presented as mean \pm SEM. The sum of the $\mathrm{HX}$ and $\mathrm{HC}$ values $(\mathrm{HX}+\mathrm{HC})$, expressed as mean $\pm \mathrm{SEM}(10 \%$ of mean), are also shown. The numbers above the $\mathrm{HX}+\mathrm{HC}$ columns are the percentage (\%) differences between the $\mathrm{HX}+\mathrm{HC}$ values and actual $\mathrm{HH}$ values. $* P<0.05$, significant response from Pre-value. ${ }^{\dagger} P<0.05$, $\mathrm{HH}$ versus $\mathrm{HX}$.

and Hanson, 1985; Easton et al., 1986; Eden and Hanson, 1987; Vizek et al., 1987; Elnazir et al., 1996; Maxová and Vízek, 2001; Stunden et al., 2001; Putnam et al., 2005; Pokorski and
Antosiewicz, 2010; Teppema and Dahan, 2010). In addition, studies have shown that CSNX blunts the HX and HC ventilatory responses in both adult and newborn animals (Chalmers et al., 


\section{SHAM rats}
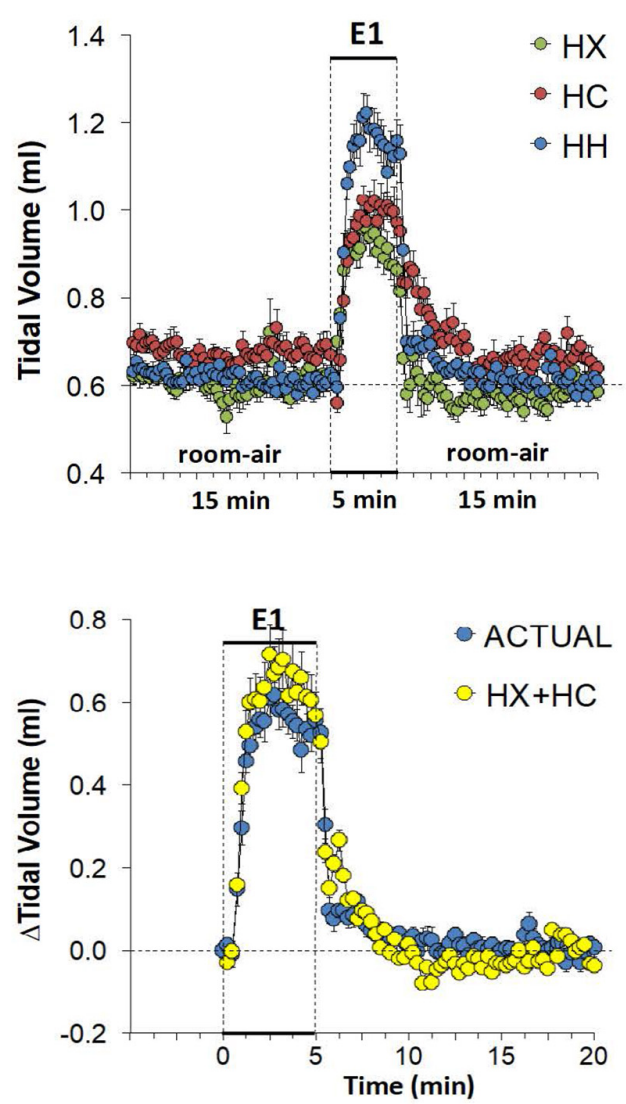

CSNX rats
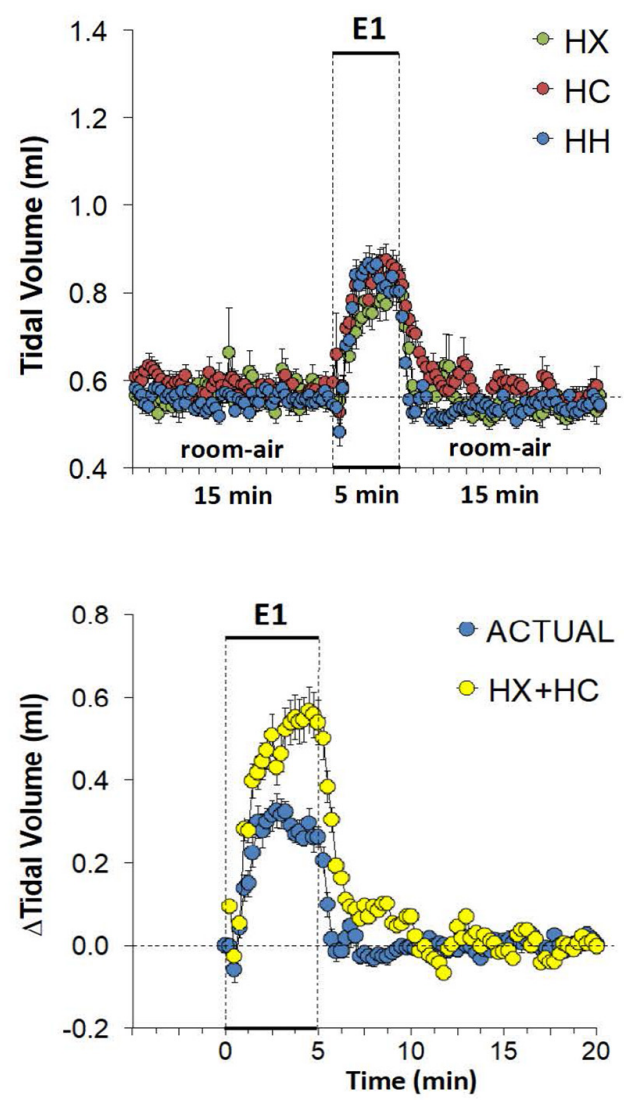

FIGURE 6 | Top panels: Tidal volume (VT) values averaged every $15 \mathrm{~s}$ in freely moving sham-operated (SHAM) rats and in rats with bilateral carotid sinus nerve transection (CSNX) during exposure to a single episode (E1) of hypoxic $\left(\mathrm{HX} ; 10 \% \mathrm{O}_{2}, 90 \% \mathrm{~N}_{2}\right)$, hypercapnic $\left(\mathrm{HC}\right.$; $\left.5 \% \mathrm{CO}_{2}, 21 \% \mathrm{O}_{2}, 74 \% \mathrm{~N}_{2}\right)$, or hypoxic-hypercapnic $\left(\mathrm{HH} ; 5 \% \mathrm{CO}_{2}, 10 \% \mathrm{O}_{2}, 85 \% \mathrm{~N}_{2}\right)$ gas challenge of $5 \mathrm{~min}$ in duration, followed by 15 min of room-air. The data are presented as mean \pm SEM. Bottom panels: Changes in VT in SHAM and CSNX rats during the actual $\mathrm{HH}$ gas challenge compared to addition of $\mathrm{HX}+\mathrm{HC}$ values. For the actual $\mathrm{HH}$ values, data are presented as mean \pm SEM and for the $\mathrm{HX}+\mathrm{HC}$ values, data are presented as the mean \pm SEM (10\% of mean).

1967; Sapru and Krieger, 1977; Cardenas and Zapata, 1983; Bureau et al., 1985; Olson et al., 1988; Suguihara et al., 1994; Fung et al., 1996; Lowry et al., 1999a,b; Teppema and Dahan, 2010; Mouradian et al., 2012; Baby et al., 2018). However, the effect of CSNX on HX (poikilocapnic), HC and hypoxiahypercapnia $(\mathrm{HH})$ ventilatory responses in juvenile (P25) rats remains unclear. Earlier studies have shown that Sprague Dawley rats at P25 are not sexually mature (Sengupta, 2013), but have fully mature peripheral and central neuronal systems (Dumas, 2005; Jiang et al., 2005; Tahayori and Koceja, 2012; Sinclair et al., 2014; Lai et al., 2016). Thus, we used the P25 age group in this study to analyze the role of peripheral $\mathrm{CB}$ chemoafferents in the ventilatory performance of juvenile rats. We hypothesized that the peripheral chemosensory pathway in juvenile rats plays a unique role in determining the interaction between $\mathrm{O}_{2}$ and $\mathrm{CO}_{2}$, and consequently, the response to hypoxic-hypercapnic gas challenges. Our present study provides compelling evidence supporting previous observations that peripheral and central chemoreflexes appear to be fully operational in Sprague Dawley
P25 rats, because we found that the $\mathrm{HX}\left(10 \% \mathrm{O}_{2}, 90 \% \mathrm{~N}_{2}\right)$ and $\mathrm{HC}\left(5 \% \mathrm{CO}_{2}, 21 \% \mathrm{O}_{2}, 90 \% \mathrm{~N}_{2}\right)$ gas challenges we exposed the $\mathrm{P} 25$ rats to elicited robust increases in $\mathrm{R}$, VT and MV in SHAM rats that resemble in many respects those observed in adult rats of various strains, including Sprague Dawley rats (Teppema and Dahan, 2010; May et al., 2013a,b).

HX and HC challenges are probes used to study and determine ventilatory signaling cascades elicited by decreases in arterial $\mathrm{pO}_{2}$ or increases in arterial $\mathrm{pCO}_{2}$, and the $\mathrm{HH}$ challenge is more physiological and clinically relevant in that it causes changes in $\mathrm{pO}_{2}$ and $\mathrm{pCO}_{2}$ blood-gas chemistry that resemble those elicited by central/obstructive sleep apneas (Smith et al., 1984, 2006, 2010, 2015; Blain et al., 2010; Forster and Smith, 2010; May et al., 2013a,b). The major objectives of this study were (1) to characterize the changes in $\mathrm{fR}, \mathrm{VT}$ and $\mathrm{MV}$ elicited by $\mathrm{HX}, \mathrm{HC}$ and $\mathrm{HH}$ in order to define and compare, how these challenges affect ventilation in juvenile rats; (2) to determine how ventilatory responses elicited by $\mathrm{HX}, \mathrm{HC}$ and $\mathrm{HH}$ are dependent on the presence of 


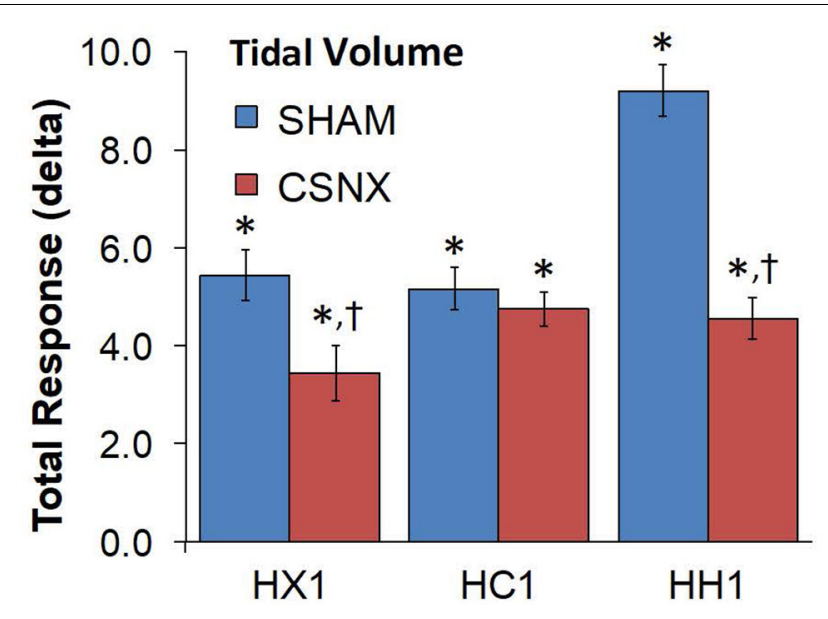

SHAM rats

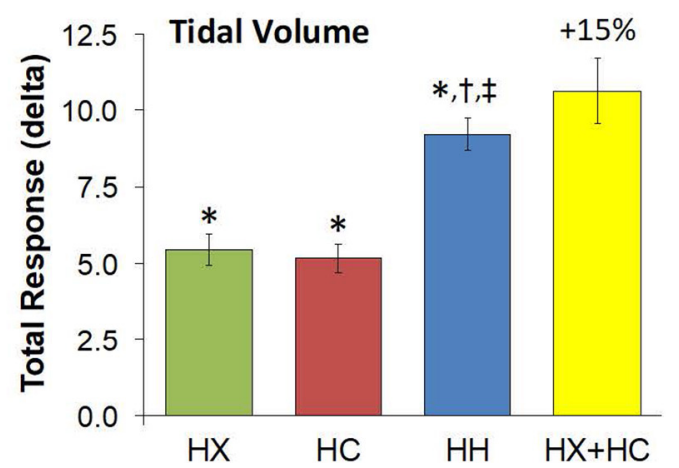

CSNX rats

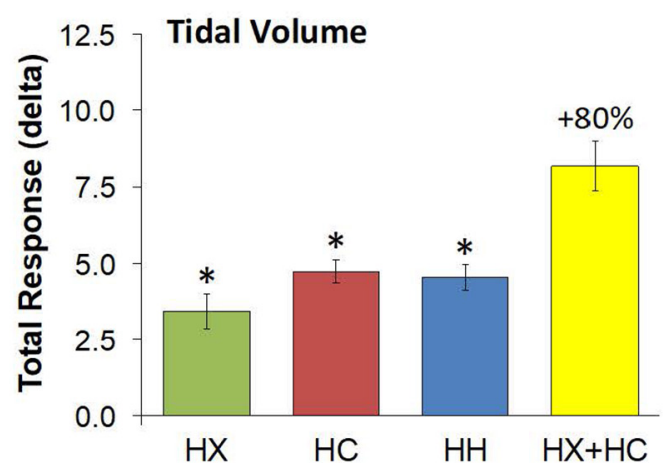

FIGURE 7 | Top panels: Total arithmetic changes in tidal volume $(\mathrm{VT})$ that occurred during exposure to a single hypoxic ( $\mathrm{HX} 1,10 \%$ O $\mathrm{O}_{2}, 90 \% \mathrm{~N}$ ), hypercapnic ( $\mathrm{HC} 1$, $\left.5 \% \mathrm{CO}_{2}, 21 \% \mathrm{O}_{2}, 74 \% \mathrm{~N}_{2}\right)$ or hypoxic-hypercapnic $\left(\mathrm{HH} 1,5 \% \mathrm{CO}_{2}, 10 \% \mathrm{O}_{2}, 85 \% \mathrm{~N}_{2}\right)$ gas challenge in SHAM and CSNX rats. The data are presented as mean \pm SEM. ${ }^{*} P<0.05$, significant response from Pre-value. ${ }^{\dagger} P<0.05$, CSNX versus SHAM. Bottom panels: Total arithmetic changes in $V T$ values in SHAM (left panel) and CSNX (right panel) rats during exposure to $\mathrm{HX}, \mathrm{HC}$ or $\mathrm{HH}$ gas challenges. The sum of the $\mathrm{HX}$ and $\mathrm{HC}$ values $(\mathrm{HX}+\mathrm{HC})$ expressed as mean $\pm \mathrm{SEM}(10 \%$ of mean) are shown. The figures in parentheses above the $\mathrm{HX}+\mathrm{HC}$ columns are the percentage (\%) differences between actual $\mathrm{HH}$ values and $\mathrm{HX}+\mathrm{HC}$ values. ${ }^{*} P<0.05$, significant response from Pre-value. ${ }^{\dagger} P<0.05, \mathrm{HH}$ versus $\mathrm{HX} .{ }^{*} P<0.05, \mathrm{HH}$ versus $\mathrm{HC}$.

CB chemoafferents; (3) to determine the interaction between HX and HC signaling pathways in SHAM rats in order to characterize whether these inputs are (a) simply additive (i.e., independent of one another), (b) synergistic (superadditive) or (c) inhibitory (hypo-additive); and (4) to determine whether the interaction between hypoxia and hypercapnia signaling pathways is under the influence of the CB-CSN chemoafferent complex (i.e., is the interaction disturbed in bilateral CSNX rats).

Our data shows that (1) the initial rate of rise (over the first $60 \mathrm{~s}$ ) in $\mathrm{fR}$, VT and MV elicited by the HX, HC and $\mathrm{HH}$ gas challenges were shallower in CSNX rats than in SHAM rats; (2) the total increases in $\mathrm{fR}, \mathrm{VT}$, and $\mathrm{MV}$ elicited by HX were diminished in CSNX rats compared to SHAM rats; (3) the total increases in $\mathrm{fR}, \mathrm{VT}$ and MV elicited by $\mathrm{HC}$ in CSNX rats were not significantly different from those in SHAM rats; and (4) the total increases in $\mathrm{fR}, \mathrm{VT}$ and $\mathrm{MV}$ elicited by $\mathrm{HH}$ observed in SHAM rats were markedly diminished in CSNX rats. These findings suggests and/or support previous evidence that (1) the activity of $\mathrm{CB}$ chemoafferents increases rapidly in response to changes in arterial blood $\mathrm{pO}_{2}$ and $\mathrm{pCO}_{2}$, thereby allowing more rapid ventilatory responses than central chemoreceptors (Fatemian et al., 2003; Smith et al., 2006), (2) the CB-CSN inputs to the cNTS play a discernible and important role in HX ventilatory signaling, while central chemoreceptors provide most of the steady-state response to elevations in blood $\mathrm{pCO}_{2}$ (Prabhakar, 2000; López-Barneo et al., 2008; Teppema and Dahan, 2010; Guyenet and Bayliss, 2015; Guyenet et al., 2019), (3) the loss of CB-CSN complexes does not impair HCinduced enhancement of ventilatory performance, and (4) the $\mathrm{VT}$ response that occurs when $\mathrm{HX}$ and $\mathrm{HC}$ challenges are given simultaneously (i.e., the $\mathrm{HH}$ gas challenge), is indeed 


\section{SHAM rats}
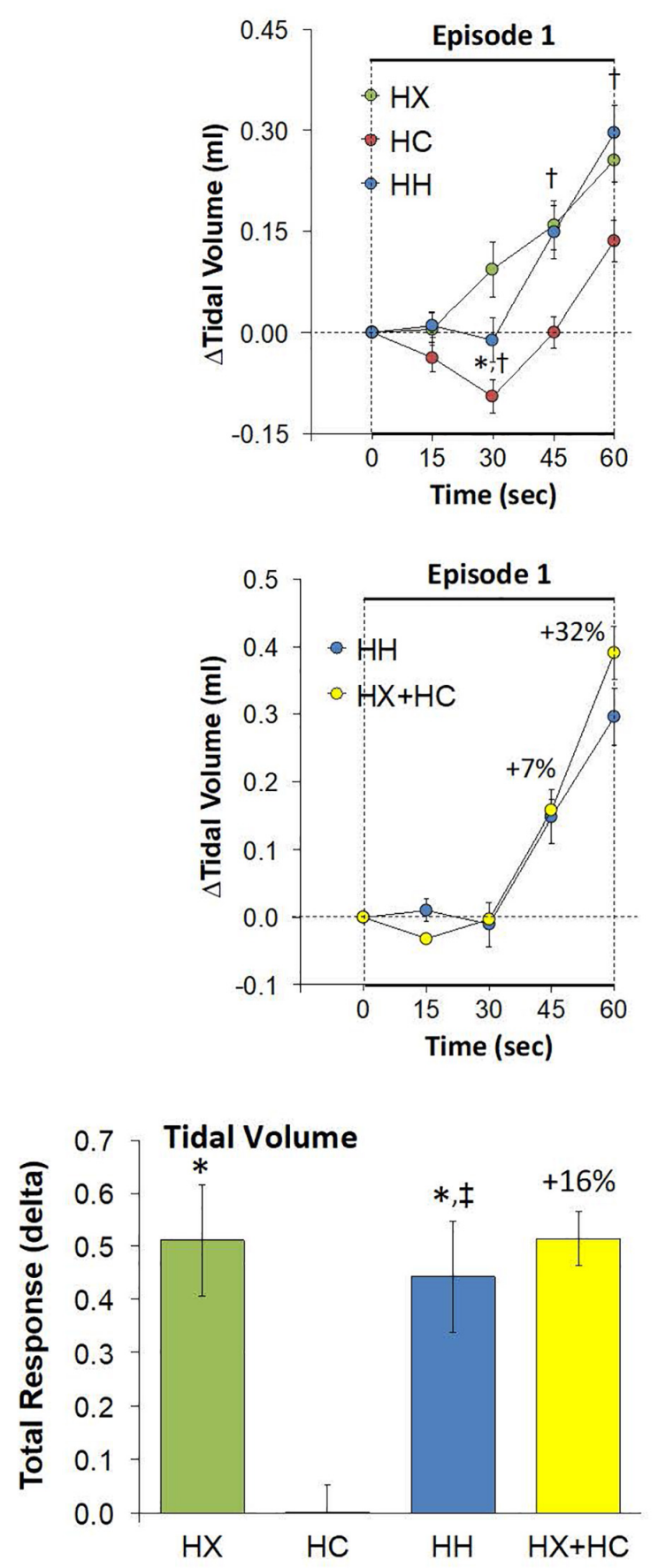

\section{CSNX rats}
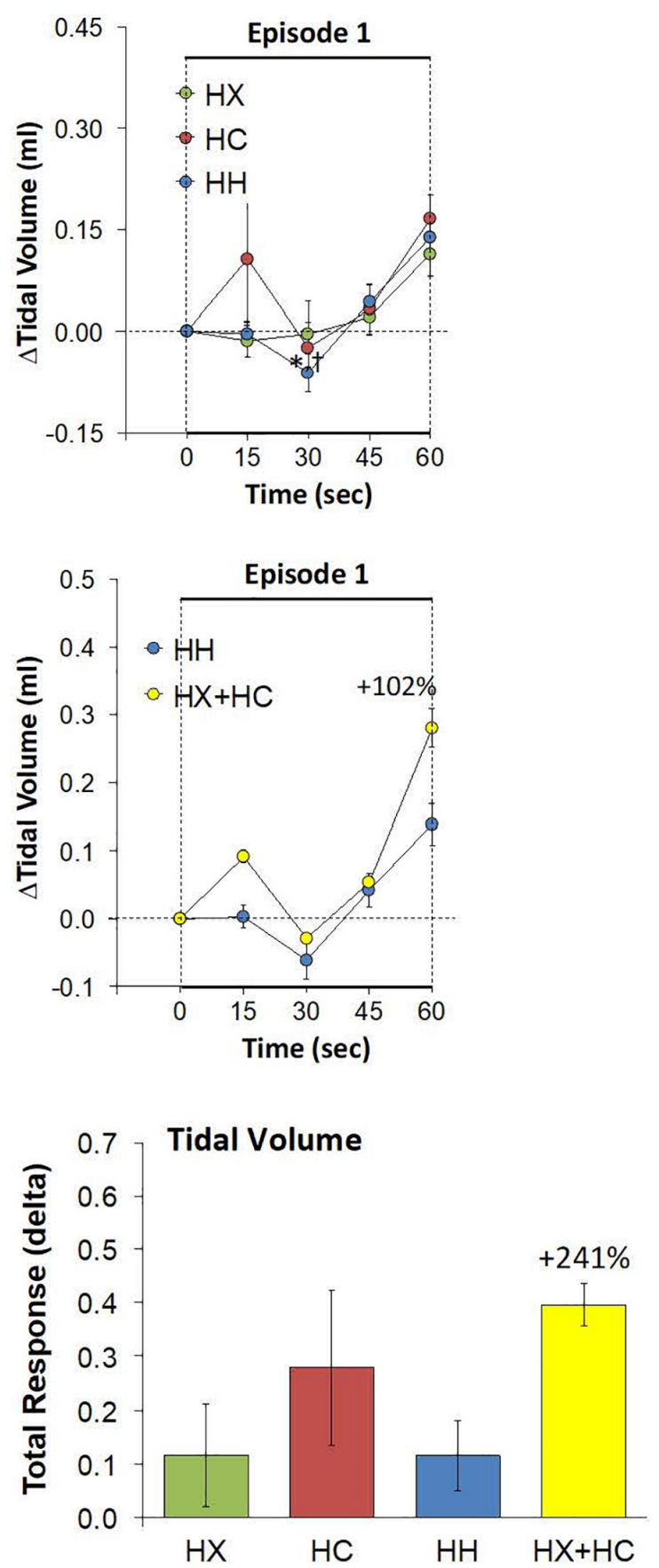

FIGURE 8 | Top panels: Arithmetic changes in tidal volume (VT) in freely moving sham-operated (SHAM) rats and in rats with bilateral carotid sinus nerve transection (CSNX) during the first $60 \mathrm{~s}$ of exposure to a single hypoxic $\left(\mathrm{HX}, 10 \% \mathrm{O}_{2}, 90 \% \mathrm{~N}_{2}\right)$, hypercapnic $\left(\mathrm{HC}, 5 \% \mathrm{CO}_{2}, 21 \% \mathrm{O}_{2}, 74 \% \mathrm{~N}_{2}\right)$, or hypoxic-hypercapnic $\left(\mathrm{HH}, 5 \% \mathrm{CO}_{2}, 10 \% \mathrm{O}_{2}, 85 \% \mathrm{~N}_{2}\right)$ gas challenge (Episode $\left.1(\mathrm{E} 1)\right)$. Data are presented as mean $\pm \mathrm{SEM}$. ${ }^{*} P<0.05, \mathrm{HH}$ versus $\mathrm{HX} .{ }^{\dagger} P<0.05$, $\mathrm{HH}$ versus HC. Middle panels: Arithmetic changes in VT in SHAM and CSNX rats during the first 60 s of the actual hypoxic-hypercapnic (HH) gas challenge values compared to addition of the $\mathrm{HX}$ and $\mathrm{HC}(\mathrm{HX}+\mathrm{HC})$ gas challenge values. For the actual $\mathrm{HH}$ values, data are shown as mean $\pm \mathrm{SEM}$ and for $\mathrm{HX}+\mathrm{HC}$ values, data are presented as the mean \pm SEM (10\% of mean). Bottom panels: Total arithmetic changes in VT in SHAM and CSNX rats during the first $60 \mathrm{~S}$ of exposure to HX, HC or $\mathrm{HH}$ gas challenges. Data are presented as mean \pm SEM. The sum of HX and HC values (HX+HC), expressed as mean $\pm \mathrm{SEM}(10 \%$ of mean), are shown. The numbers above the $\mathrm{HX}+\mathrm{HC}$ columns are the percentage (\%) differences between the $\mathrm{HX}+\mathrm{HC}$ values and actual $\mathrm{HH}$ values. $* P<0.05$, significant response from Pre-value. ${ }^{\dagger} P<0.05, \mathrm{HH}$ versus $\mathrm{HX} .{ }^{\ddagger} P<0.05, \mathrm{HH}$ versus $\mathrm{HC}$. 


\section{SHAM rats}
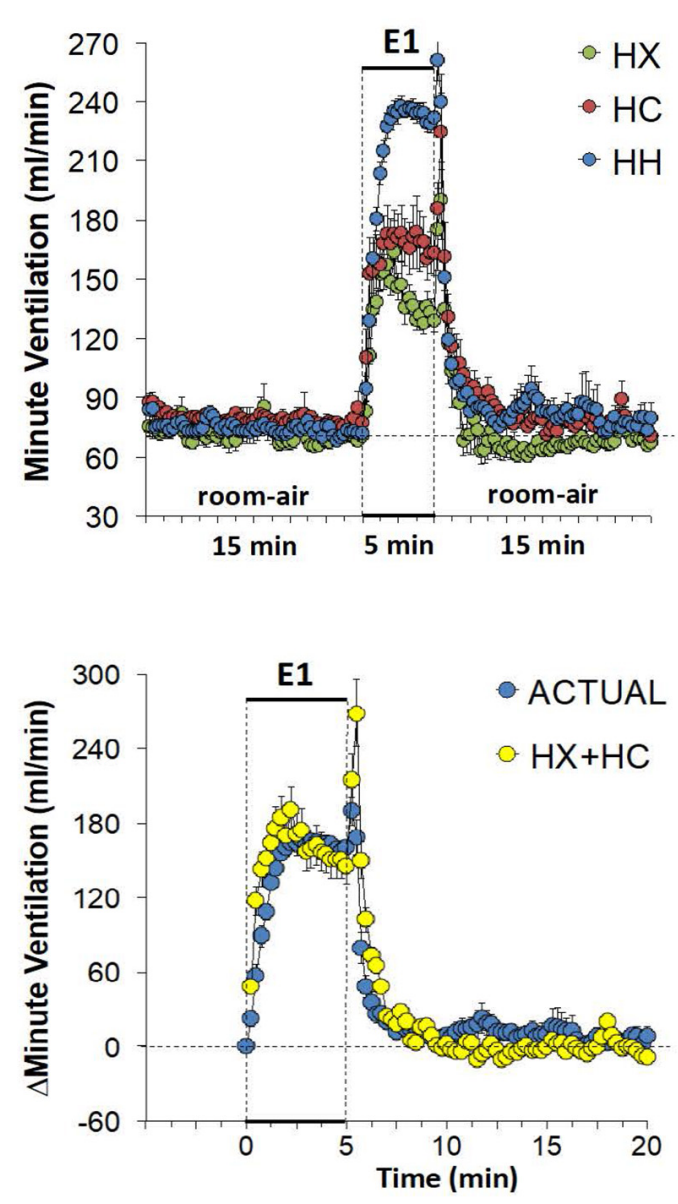

\section{CSNX rats}
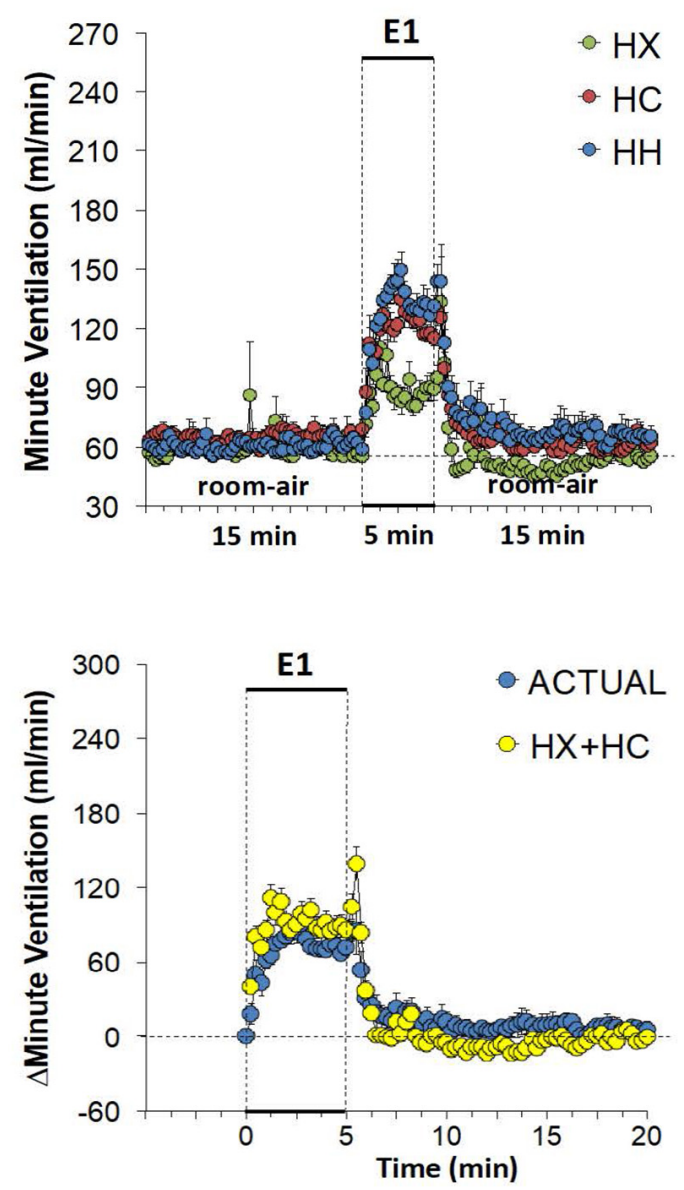

FIGURE 9 | Top panels: Minute ventilation (MV) values averaged every $15 \mathrm{~s}$ in freely moving sham-operated (SHAM) rats and in rats with bilateral carotid sinus nerve transection (CSNX) during exposure to a single episode (E1) of hypoxic $\left(\mathrm{HX} ; 10 \% \mathrm{O}_{2}, 90 \% \mathrm{~N}_{2}\right)$, hypercapnic $\left(\mathrm{HC} ; 5 \% \mathrm{CO}_{2}, 21 \% \mathrm{O}_{2}, 74 \% \mathrm{~N}_{2}\right)$, or hypoxic-hypercapnic $\left(\mathrm{HH} ; 5 \% \mathrm{CO}_{2}, 10 \% \mathrm{O}_{2}, 85 \% \mathrm{~N}_{2}\right)$ gas challenge of 5 min in duration, followed by 15 min of room-air. The data are presented as mean $\pm \mathrm{SEM}$. Bottom panels: Changes in MV in SHAM and CSNX rats during the actual $\mathrm{HH}$ gas challenge compared to addition of $\mathrm{HX}+\mathrm{HC}$ values. For the actual $\mathrm{HH}$ values, data are presented as mean \pm SEM and for the $\mathrm{HX}+\mathrm{HC}$ values, data are presented as the mean \pm SEM (10\% of mean).

additive and this additivity is clearly dependent upon the CBCSN input to the cNTS as well as direct activation of the retrotrapezoid nucleus (RTN) (Smith et al., 1984, 2006, 2010, 2015; Blain et al., 2010; Forster and Smith, 2010). However, it must be noted that the interactions of the cNTS and RTN with other key nuclei within the brainstem will most likely be of vital importance to the expression of the observed ventilatory responses. Moreover, the relative role of astrocytes and neurons in the brainstem with respect to hypercapnic signaling and the interaction of hypercapnic and hypoxic signaling pathways must also be considered (Sheikhbahaei et al., 2016; Turovsky et al., 2016).

Furthermore, in SHAM rats, the total responses that occurred during the actual $\mathrm{HH}$ gas challenge were equal to simple addition of actual $\mathrm{HX}$ and $\mathrm{HC}$ values (i.e., $\mathrm{HX}+\mathrm{HC}$ responses). The exception was that the initial increases in $\mathrm{fR}$ elicited by $\mathrm{HH}$ were less than would be predicted by addition of the
HX and HC responses. Thus, our evidence for additivity is consistent with a previous study done in cats showing that when HX and HC stimuli are given together (i.e., HH stimuli), the interaction between central and peripheral chemoreceptors is additive in that one stimulus, $\mathrm{HX}$ or $\mathrm{HC}$, simply adds to the other (Eldridge et al., 1981). However, our observation for additivity in P25 rats contradicts previous findings that (1) a positive (synergistic) interaction between hypoxia- and hypercapnia-induced neuronal signaling in cats exists at the level of the CB (Eyzaguirre and Lewin, 1961); (2) in adult dogs (no relevant data in adult rats) that peripheral $\mathrm{CB}$ and central chemoreceptors are functionally inter-dependent such that activity and/or sensitivity of medullary chemoreceptors is determined by input from CB chemoreceptors and vice versa (Fencl et al., 1966; Smith et al., 1984, 2006, 2010, 2015; Dempsey, 2005; Blain et al., 2010; Forster and Smith, 2010); and (3) interaction between central and peripheral 


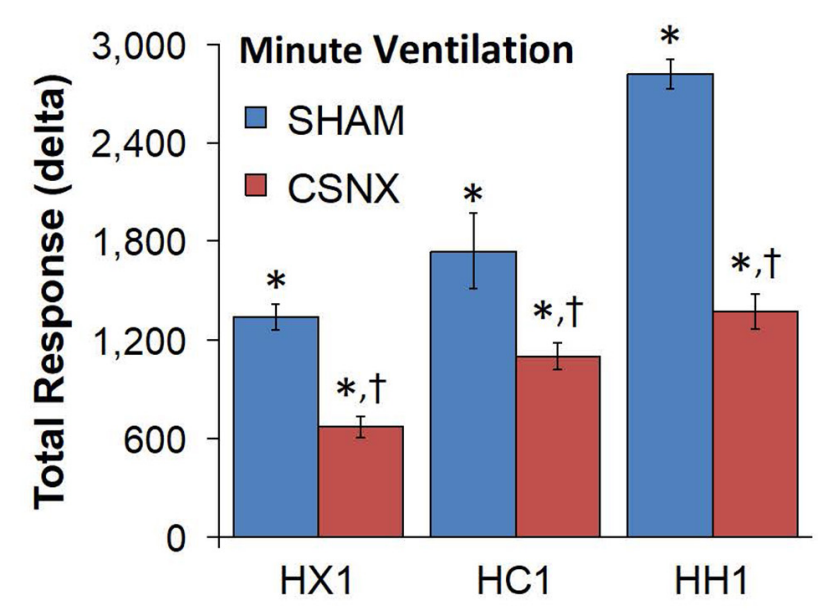

\section{SHAM rats}

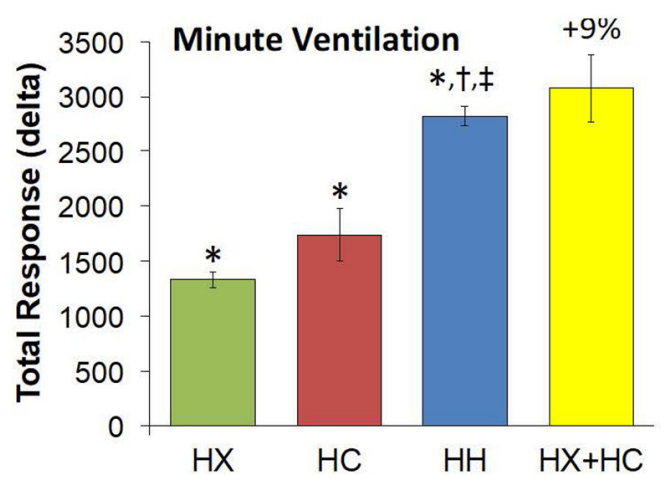

CSNX rats

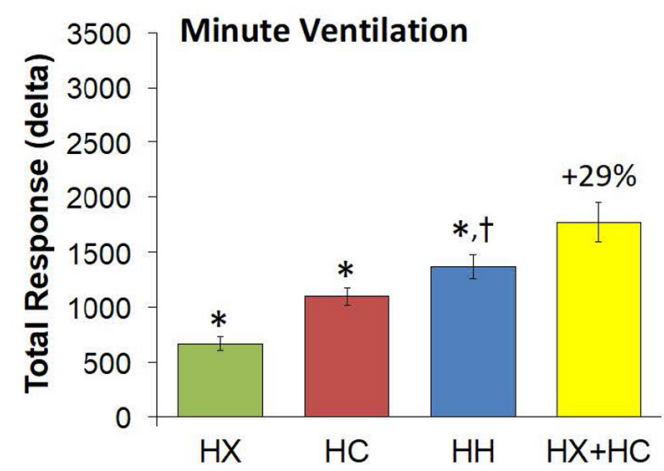

FIGURE 10 | Top panels: Total arithmetic changes in minute ventilation (MV) that occurred during exposure to a single hypoxic ( $\mathrm{HX} 1,10 \%$ O hypercapnic $\left(\mathrm{HC} 1,5 \% \mathrm{CO}_{2}, 21 \% \mathrm{O}_{2}, 74 \% \mathrm{~N}_{2}\right)$ or hypoxic-hypercapnic $\left(\mathrm{HH} 1,5 \% \mathrm{CO}_{2}, 10 \% \mathrm{O}_{2}, 85 \% \mathrm{~N}_{2}\right)$ gas challenge in SHAM and CSNX rats. The data are presented as mean \pm SEM. ${ }^{*} P<0.05$, significant response from Pre-value. ${ }^{\dagger} P<0.05$, CSNX versus SHAM. Bottom panels: Total arithmetic changes in MV in SHAM (left panel) and CSNX (right panel) rats during exposure to the $\mathrm{HX}, \mathrm{HC}$ or $\mathrm{HH}$ gas challenges. The sum of $\mathrm{HX}$ and $\mathrm{HC}$ values (HX+HC) expressed as mean \pm SEM (10\% of mean) are shown. The figures in parentheses above the $H X+H C$ columns are the percentage (\%) differences between actual $H H$ values and $\mathrm{HX}+\mathrm{HC}$ values. ${ }^{*} P<0.05$, significant response from Pre-value. ${ }^{\dagger} P<0.05, \mathrm{HH}$ versus $\mathrm{HX} .{ }^{\ddagger} P<0.05$, $\mathrm{HH}$ versus $\mathrm{HC}$.

chemoreceptors in cats and rabbits is negative (i.e., the stimuli interact in a hypo-additive manner) (Eldridge, 1974; KiwullSchöne et al., 1976). In addition, it is evident from this study that $\mathrm{fR}, \mathrm{VT}$ and MV responses elicited by $\mathrm{HH}$ did not reach the maximum values (i.e., ceiling values) that the rats were capable of achieving throughout the entire $5 \times 5$ $\mathrm{HX}, \mathrm{HC}$ or $\mathrm{HH}$ gas challenge (i.e., maximum values observed when the rats are grooming, exploring, or in a possible state of elevated vigilance in response to an unexpected external stimulus, such as a sound that the rats could hear, remembering that they were housed in plexi-glass chambers in a quiet room to control for external noise disturbances). Indeed, the markedly smaller than expected increase in $\mathrm{fR}$ elicited by $\mathrm{HH}$ gas challenge was not simply because the rats could not attain higher values. These findings therefore suggest that $\mathrm{HH}$ only recruits ventilatory pathways that have a set-point with respect to the maximum levels of responses that can be achieved.

It should be noted that the P25 rats used for these plethysmography studies were awake and quietly resting before and during the $\mathrm{HX}, \mathrm{HC}$ and $\mathrm{HH}$ gas challenges. This is important to mention because the awake-sleep state of the rat can influence the magnitude of ventilatory responses to direct brain stimulation and in response to HX and HC gas challenges (Abbott et al., 2013). In particular, the ventilatory responses seen during awake and non-REM sleep stages are similar, but markedly blunted during REM sleep. In our studies, none of the rats were asleep at any stages of the study and as such we do not believe that the data was influenced by the awake-sleep status of the rats. In addition, it should be noted that robust ventilatory responses to a poikilocapnic HX gas challenge were evident in the juvenile (P25) rats with prior bilateral CSNX. This finding differs strikingly to 


\section{SHAM rats}
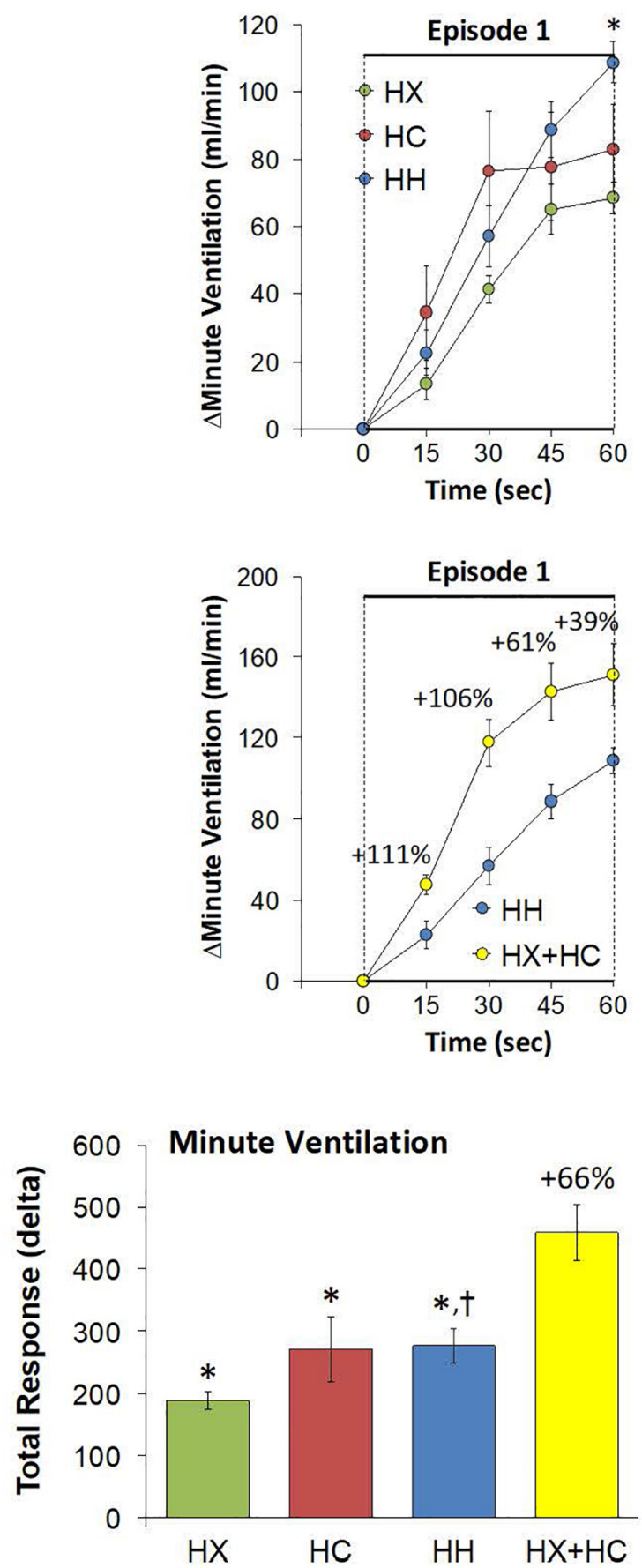

CSNX rats
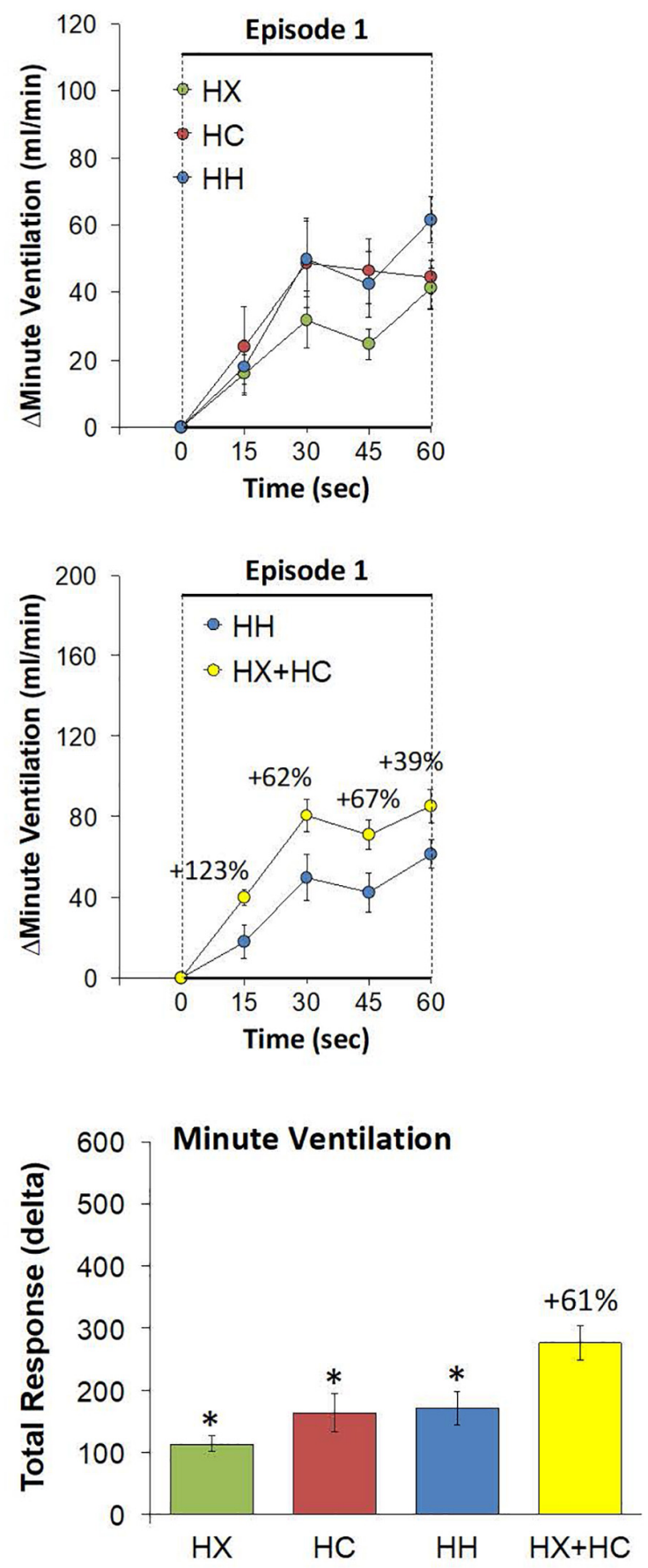

FIGURE 11 | Top panels: Arithmetic changes in minute ventilation (MV) in freely moving sham-operated (SHAM) rats and in rats with bilateral carotid sinus nerve transection (CSNX) during the first $60 \mathrm{~s}$ of exposure to a single hypoxic $\left(\mathrm{HX}, 10 \% \mathrm{O}_{2}, 90 \% \mathrm{~N}_{2}\right)$, hypercapnic $\left(\mathrm{HC}, 5 \% \mathrm{CO}_{2}, 21 \% \mathrm{O}_{2}, 74 \% \mathrm{~N}_{2}\right)$, or hypoxic-hypercapnic $\left(\mathrm{HH}, 5 \% \mathrm{CO}_{2}, 10 \% \mathrm{O}_{2}, 85 \% \mathrm{~N}_{2}\right)$ gas challenge (Episode $\left.1(\mathrm{E} 1)\right)$. Data are presented as mean $\pm \mathrm{SEM} .{ }^{*} P<0.05, \mathrm{HH}$ versus $\mathrm{HX}$. ${ }^{\dagger} P<0.05$, $\mathrm{HH}$ versus $\mathrm{HC}$. Middle panels: Arithmetic changes in MV in SHAM and CSNX rats during the first 60 s of the actual hypoxic-hypercapnic (HH) gas challenge values compared to addition of the $\mathrm{HX}$ and $\mathrm{HC}(\mathrm{HX}+\mathrm{HC})$ gas challenge values. For the actual $\mathrm{HH}$ values, data are shown as mean $\pm \mathrm{SEM}$ and for $\mathrm{HX}+\mathrm{HC}$ values, data are presented as the mean \pm SEM (10\% of mean). Bottom panels: Total arithmetic changes in MV in SHAM and CSNX rats during the first 60 s of exposure to HX, HC or $\mathrm{HH}$ gas challenges. The data are presented as mean \pm SEM. The sum of the $\mathrm{HX}$ and $\mathrm{HC}$ values $(\mathrm{HX}+\mathrm{HC})$, expressed as mean $\pm \mathrm{SEM}(10 \%$ of mean), are also shown. The numbers above the $\mathrm{HX}+\mathrm{HC}$ columns are the percentage (\%) differences between the $\mathrm{HX}+\mathrm{HC}$ values and actual $\mathrm{HH}$ values. ${ }^{*} P<0.05$, significant response from Pre-value. ${ }^{\dagger} P<0.05, \mathrm{HH}$ versus $\mathrm{HX}$. 


\section{CSN Intact}
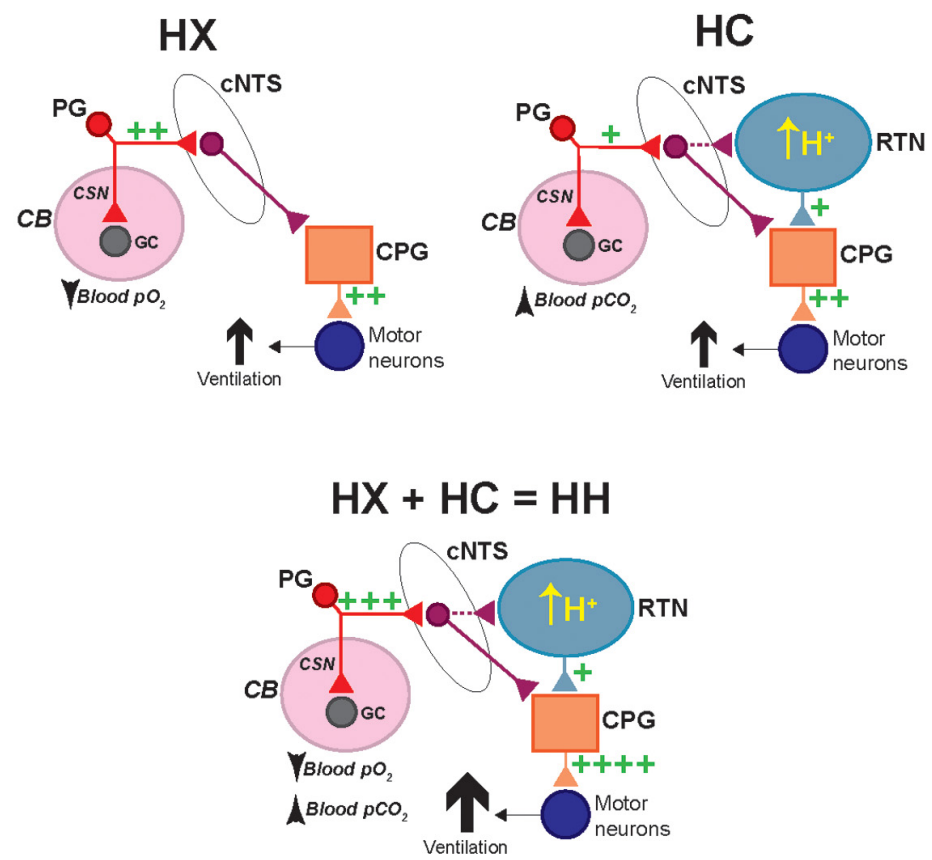

\section{CSN Transected}
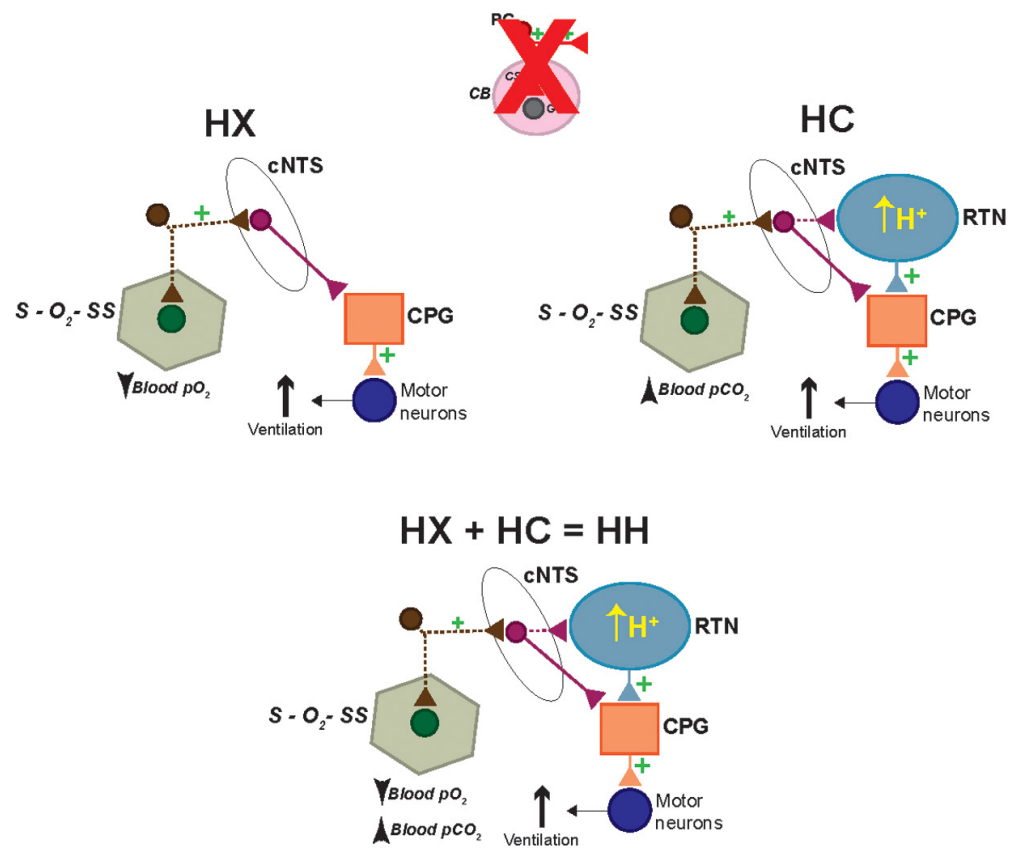

FIGURE 12 | Schematic describing how activation of hypoxic and hypercapnic signaling pathways increase ventilation in P25 male SD rats in a simple additive manner and how this additivity is lost with prior CSN transection. HX, hypoxic gas challenge. HC, hypercapnic gas challenge. HH, hypoxic-hypercapnic gas challenge. CB, carotid body. GC, glomus cell. CSN, carotid sinus chemoafferent nerve. PG, petrosal ganglion cell body of the chemoafferent nerve. cNTS, commissural nucleus tractus solitarius. RTN, retrotrapezoid nucleus. CPG, central pattern generator. 
the much more dramatic loss of ventilatory responses to HX gas challenge in adult rats and mice (Bisgard et al., 1976; Sapru and Krieger, 1977; Smith and Mills, 1980; Martin-Body et al., 1985, 1986; Olson et al., 1988; Roux et al., 2000; Baby et al., 2018). Whether the remaining ventilatory responses to HX challenge in P25 rats with bilateral CSNX is due to (1) low secondary $\mathrm{O}_{2}$-sensing structures, such as aortic bodies or peripheral (e.g., glossopharyngeal) nerves (Eyzaguirre and Lewin, 1961); (2) the dynamic functional reorganization of central chemoreceptor reflex pathways (Roux et al., 2000); and/or (3) central $\mathrm{O}_{2}$ sensors (Dillon and Waldrop, 1993; Sun and Reis, 1994), remains to be determined. Finally, our data suggesting that loss of CSN input to the brainstem markedly impairs the additivity of the hypoxic-hypercapnic ventilatory response, may have important implications for the development of disease processes whereby the loss of function of the CBs and/or CSN chemoafferents contributes to changes in ventilation in unexpected ways.

\section{Study Limitations}

An important limitation of this study is that it only provides a snapshot of the temporal changes in ventilatory responses to $\mathrm{HX}, \mathrm{HC}$ and $\mathrm{HH}$ gas challenges after bilateral CSNX. The 4-day recovery period was chosen because we wanted to expose the $\mathrm{P} 25$ rats to $\mathrm{HX}, \mathrm{HC}$ and $\mathrm{HH}$ challenges before the diminished ventilatory responses to $\mathrm{HX}$ challenges are known to return to their full expression, which is about 2-3 weeks post-CSNX (Bisgard et al., 1976; Smith and Mills, 1980; Martin-Body et al., 1985, 1986; Sinclair, 1987; Dillon and Waldrop, 1993). Another limitation is that although we used standard HX $\left(10 \% \mathrm{O}_{2}, 90 \%\right.$ $\left.\mathrm{N}_{2}\right)$, $\mathrm{HC}\left(5 \% \mathrm{CO}_{2}, 21 \% \mathrm{O}_{2}, 74 \% \mathrm{~N}_{2}\right)$ and $\mathrm{HH}\left(10 \% \mathrm{O}_{2}, 5 \% \mathrm{CO}_{2}\right.$, $85 \% \mathrm{~N}_{2}$ ) gas mixtures, important information may have been obtained with different combinations of these gases. In addition, the lack of female rats in this study is noted and will be rectified in future studies to determine whether female rats of age P25 show different responses to males at a time when sex hormones are not major drivers of physiological status. Finally, we need to mention that baroreceptor afferents within the CSN combine with those in the aortic depressor nerve to regulate arterial blood pressure (Del Rio et al., 2016), and therefore another important limitation of the present study is that we did not assess the cardiovascular responses, sympatho-vagal balance or baroreceptor reflex activity before or during the gas challenges in the SHAM or CSNX rats. The role of the baroreceptor afferents within the CSN and the consequences of their loss following bilateral CSNX to ventilatory responses of $\mathrm{HX}, \mathrm{HC}$ and $\mathrm{HH}$ gas challenges will be looked at in future studies.

\section{CONCLUSION}

Overall, this novel data reveals that the CSN provides necessary input to respiratory control regions in the brainstem of juvenile (P25) rats in order to induce $\mathrm{HX}, \mathrm{HC}$ and $\mathrm{HH}$ ventilatory responses. In addition, our data suggests that juvenile rats with prior CSNX possess a functional secondary means of low $\mathrm{O}_{2}$ sensing, other than the CB-CSN complex, that also send signals to respiratory control centers of the brainstem to trigger downstream respiratory reflexes. Finally, our results reveal that additive between $\mathrm{HX}$ and $\mathrm{HC}$ stimuli is absent in rats with CSNX, therefore suggesting that loss of CSN chemoafferent signaling to the brainstem allows central $\mathrm{CO}_{2}$ chemoreceptors to dominate the low secondary $\mathrm{O}_{2}$ sensing input at the points of convergence between the central and peripheral chemoreceptor input.

In conclusion we have comprised a series of schematics describing how $\mathrm{HX}$ and $\mathrm{HC}$ signaling pathways increase ventilation in P25 male rats with the CSN intact and CSN transected (Figure 12). In SHAM rats (i.e., CSN intact), a hypoxic gas challenge $(\mathrm{HX})$ triggers a strong $(++)$ depolarization of chemosensitive glomus cells (GC) in the $\mathrm{CB}$ that causes the release of excitatory neurotransmitters. These neurotransmitters then activate chemosensory afferent fibers in the CSN, whose cell bodies are located in the petrosal ganglion (PG). The central projections of these chemoafferents signal neurons in the commissural nucleus tractus solitarius (cNTS), which relay downstream respiratory-related neuronal pathways in the central pattern generator $(\mathrm{CPG})$ to increase ventilation $(++)$ in an effort to restore blood gas homeostasis. A hypercapnic gas challenge $(\mathrm{HC})$ triggers a moderate $(+)$ depolarization, and release of neurotransmitters from chemosensitive GC in the CB. In addition, HC triggers a moderate $(+)$ depolarization and release of neurotransmitters from central chemosensors in the retrotrapezoid nucleus (RTN). Both signaling pathways converge in the CPG to ultimately increase ventilation $(++)$. A hypoxic-hypercapnic gas challenge $(\mathrm{HH})$ triggers a larger $(+++)$ depolarization compared to $\mathrm{HX}$ and release of neurotransmitters from chemosensitive GC in the CB. This is due to the positive interaction between hypoxia and hypercapnia when given together at the level of the CB. In addition, $\mathrm{HH}$ triggers a moderate $(+)$ depolarization and release of neurotransmitters from central chemosensors in the RTN. Both signaling pathways converge in the central pattern generator $(\mathrm{CPG})$ to ultimately cause an even greater increase ventilation $(++++)$ that is additive of the $\mathrm{HX}$ and $\mathrm{HC}$ signaling pathways.

In CSNX rats (i.e., CSN transected), HX triggers secondary $\mathrm{O}_{2}$-sensing structures $\left(\mathrm{S}-\mathrm{O}_{2}-\mathrm{SS}\right)$ that, for the sake of argument, may synapse within the cNTS. This $\mathrm{S}-\mathrm{O}_{2}-\mathrm{SS}$ input causes a moderate $(+)$ activation of cNTS neurons compared to the strong $(++)$ activation of the CSN chemoafferent input. The cNTS then signals downstream respiratory-related neuronal pathways in the CPG to increase ventilation (+). A HC triggers a smaller (+) depolarization, and release of neurotransmitters from $\mathrm{S}-\mathrm{O}_{2}-\mathrm{SS}$, compared to CSN chemoafferent input. In addition, it triggers a moderate $(+)$ depolarization from central chemosensors in the RTN. Both pathways converge in the CPG with the input from the RTN occluding the input from the $\mathrm{S}-\mathrm{O}_{2}-\mathrm{SS}$. As such, the increase in ventilation $(+)$ is mediated solely by the central chemoreceptors, and thus the additivity that is seen when the CSN is intact is lost. Finally, $\mathrm{HH}$ triggers a smaller (+) depolarization, and release of neurotransmitters from $\mathrm{S}-\mathrm{O}_{2}-\mathrm{SS}$, compared to CSN chemoafferent input. In addition, it triggers a moderate $(+)$ depolarization from central chemosensors in the RTN. Both pathways converge in the CPG with the 
input from the RTN occluding the input from the $\mathrm{S}-\mathrm{O}_{2}-\mathrm{SS}$. As such, the increase in ventilation $(+)$ is mediated solely by the central chemoreceptors, and thus the additivity that is seen when the CSN is intact is again lost. We understand that these schematics are rudimentary, and that there are many other plausible possibilities to explain our data for (1) the additivity of HX and HC signaling pathways in SHAM rats; and (2) the loss of this additivity in CSNX rats. We are sure that this series of schematics will evolve as new data is collected.

\section{DATA AVAILABILITY STATEMENT}

The raw data supporting the conclusions of this article will be made available by the authors, without undue reservation.

\section{ETHICS STATEMENT}

The animal study was reviewed and approved by the Case Western Reserve University Animal Care and Use Committee.

\section{REFERENCES}

Abbott, S. B., Coates, M. B., Stornetta, R. L., and Guyenet, P. G. (2013). Optogenetic stimulation of $\mathrm{cl}$ and retrotrapezoid nucleus neurons causes sleep statedependent cardiorespiratory stimulation and arousal in rats. Hypertension 61, 835-841. doi: 10.1161/HYPERTENSIONAHA.111.00860

Baby, S. M., Gruber, R. B., Young, A. P., MacFarlane, P. M., Teppema, L. J., and Lewis, S. J. (2018). Bilateral carotid sinus nerve transection exacerbates morphine-induced respiratory depression. Eur. J. Pharmacol. 834, 17-29. doi: 10.1016/j.ejphar.2018.07.018

Bisgard, G. E., Forster, H. V., and Klein, J. P. (1980). Recovery of peripheral chemoreceptor function after denervation in ponies. J. Appl. Physiol. Respir. Environ. Exerc. Physiol. 49, 964-970. doi: 10.1152/jappl.1980.49.6.964

Bisgard, G. E., Forster, H. V., Orr, J. A., Buss, D. D., Rawlings, C. A., and Rasmussen, B. (1976). Hypoventilation in ponies after carotid body denervation. J. Appl. Physiol. 40, 184-190. doi: 10.1152/jappl.1976.40.2.184

Blain, G. M., Smith, C. A., Henderson, K. S., and Dempsey, J. A. (2010). Peripheral chemoreceptors determine the respiratory sensitivity of central chemoreceptors to CO2. J. Physiol. 588, 2455-2471. doi: 10.1113/jphysiol.2010.187211

Bonora, M., Marlot, D., Gautier, H., and Duron, B. (1984). Effects of hypoxia on ventilation during postnatal development in conscious kittens. J. Appl. Physiol. Respir. Environ. Exerc. Physiol. 56, 1464-1471. doi: 10.1152/jappl.1984.56.6. 1464

Bureau, M. A., Lamarche, J., Foulon, P., and Dalle, D. (1985). The ventilatory response to hypoxia in the newborn lamb after carotid body denervation. Respir. Physiol. 60, 109-119. doi: 10.1016/0034-5687(85)90043-x

Bureau, M. A., Zinman, R., Foulon, P., and Begin, R. (1984). Diphasic ventilatory response to hypoxia in newborn lambs. J. Appl. Physiol. Respir. Environ. Exerc. Physiol. 56, 84-90. doi: 10.1152/jappl.1984.56.1.84

Cardenas, H., and Zapata, P. (1983). Ventilatory reflexes originated from carotid and extracarotid chemoreceptors in rats. Am. J. Physiol. 244, R119-R125. doi: 10.1152/ajpregu.1983.244.1.R119

Chalmers, J. P., Korner, P. I., and White, S. W. (1967). The relative roles of the aortic and carotid sinus nerves in the rabbit in the control of respiration and circulation during arterial hypoxia and hypercapnia. J. Physiol. 188, 435-450. doi: 10.1113/jphysiol.1967.sp008148

Del Rio, R., Andrade, D. C., Lucero, C., Arias, P., and Iturriaga, R. (2016). Carotid body ablation abrogates hypertension and autonomic alterations induced by intermittent hypoxia in rats. Hypertension 68, 436-445. doi: 10 . 1161/HYPERTENSIONAHA.116.07255

\section{AUTHOR CONTRIBUTIONS}

PG and SL conceived and designed the study, analyzed the data, and prepared the figures. PG and GC performed the surgeries and plethysmography studies. All authors contributed to writing the manuscript, and revised, read, and approved the final version of the manuscript.

\section{FUNDING}

This study was funded by an NIH-SPARC award to SL (10T20D023860; Functional Mapping of the afferent and Efferent Projections of the Superior Cervical Ganglion Interactome).

\section{ACKNOWLEDGMENTS}

The authors wish to thank Dr. James N. Bates (Department of Anesthesia, University of Iowa) for his critical comments about the manuscript and helping with the clinical perspectives of the study.

Dempsey, J. A. (2005). Crossing the apnoeic threshold: causes and consequences. Exp. Physiol. 90, 13-24. doi: 10.1113/expphysiol.2004.028985

Dillon, G. H., and Waldrop, T. G. (1993). Responses of feline caudal hypothalamic cardiorespiratory neurons to hypoxia and hypercapnia. Exp. Brain Res. 96, 260-272. doi: 10.1007/BF00227106

Dumas, T. C. (2005). Late postnatal maturation of excitatory synaptic transmission permits adult-like expression of hippocampal-dependent behaviors. Hippocampus 15, 562-578. doi: 10.1002/hipo.20077

Easton, P. A., Slykerman, L. J., and Anthonisen, N. R. (1986). Ventilatory response to sustained hypoxia in normal adults. J. Appl. Physiol. 61, 906-911. doi: 10. 1152/jappl.1986.61.3.906

Eden, G. J., and Hanson, M. A. (1987). Maturation of the respiratory response to acute hypoxia in the newborn rat. J. Physiol. 392, 1-9. doi: 10.1113/jphysiol. 1987.sp016765

Eldridge, F. L. (1974). Central neural respiratory stimulatory effect of active respiration. J. Appl. Physiol. 37, 723-735. doi: 10.1152/jappl.1974.37. 5.723

Eldridge, F. L., Gill-Kumar, P., and Millhorn, D. E. (1981). Input-output relationships of central neural circuits involved in respiration in cats. J. Physiol. 311, 81-95. doi: 10.1113/jphysiol.1981.sp013574

Elnazir, B., Marshall, J. M., and Kumar, P. (1996). Postnatal development of the pattern of respiratory and cardiovascular response to systemic hypoxia in the piglet: the roles of adenosine. J. Physiol. 492, 573-585. doi: 10.1113/jphysiol. 1996.sp021330

Eyzaguirre, C., and Lewin, J. (1961). Chemoreceptor activity of the carotid body of the cat. J. Physiol. 159, 222-237. doi: 10.1113/jphysiol.1961.sp006804

Eyzaguirre, C., and Zapata, P. (1984). Perspectives in carotid body research. J. Appl. Physiol. Respir. Environ. Exerc. Physiol. 57, 931-957. doi: 10.1152/jappl.1984.57. 4.931

Fatemian, M., Nieuwenhuijs, D. J., Teppema, L. J., Meinesz, S., van der Mey, A. G., Dahan, A., et al. (2003). The respiratory response to carbon dioxide in humans with unilateral and bilateral resections of the carotid bodies. J. Physiol. 549, 965-973. doi: 10.1113/jphysiol.2003.042259

Fencl, V., Miller, T. B., and Pappenheimer, J. R. (1966). Studies on the respiratory response to disturbances of acid-base balance, with deductions concerning the ionic composition of cerebral interstitial fluid. Am. J. Physiol. 210, 459-472. doi: 10.1152/ajplegacy.1966.210.3.459

Forster, H. V. (2003). Plasticity in the control of breathing following sensory denervation. J. Appl. Physiol. 94, 784-794. doi: 10.1152/japplphysiol.00602. 2002 
Forster, H. V., and Smith, C. A. (2010). Contributions of central and peripheral chemoreceptors to the ventilatory response to $\mathrm{CO} 2 / \mathrm{H}+$. J. Appl. Physiol. 108, 989-994. doi: 10.1152/japplphysiol.01059.2009

Fung, M. L., Wang, W., Darnall, R. A., and St John, W. M. (1996). Characterization of ventilatory responses to hypoxia in neonatal rats. Respir. Physiol. 103, 57-66. doi: 10.1016/0034-5687(95)00077-1

Gaston, B., May, W. J., Sullivan, S., Yemen, S., Marozkina, N. V., Palmer, L. A., et al. (2014). Essential role of hemoglobin beta-93-cysteine in posthypoxia facilitation of breathing in conscious mice. J. Appl. Physiol. 116, 1290-1299. doi: 10.1152/japplphysiol.01050.2013

Getsy, P. M., Davis, J., Coffee, G. A., May, W. J., Palmer, L. A., Strohl, K. P., et al. (2014). Enhanced non-eupneic breathing following hypoxic, hypercapnic or hypoxic-hypercapnic gas challenges in conscious mice. Respir. Physiol. Neurobiol. 204, 147-159. doi: 10.1016/j.resp.2014.09.006

Gonzalez, C., Almaraz, L., Obeso, A., and Rigual, R. (1994). Carotid body chemoreceptors: from natural stimuli to sensory discharges. Physiol. Rev. 74, 829-898. doi: 10.1152/physrev.1994.74.4.829

Guyenet, P. G., and Bayliss, D. A. (2015). Neural control of breathing and CO2 homeostasis. Neuron 87, 946-961. doi: 10.1016/j.neuron.2015.08.001

Guyenet, P. G., Stornetta, R. L., Souza, G., Abbott, S., Shi, Y., and Bayliss, D. A. (2019). The retrotrapezoid nucleus: central chemoreceptor and regulator of breathing automaticity. Trends Neurosci. 42, 807-824. doi: 10.1016/j.tins.2019. 09.002

Henderson, F., May, W. J., Gruber, R. B., Discala, J. F., Puskovic, V., Young, A. P., et al. (2014). Role of central and peripheral opiate receptors in the effects of fentanyl on analgesia, ventilation and arterial blood-gas chemistry in conscious rats. Respir. Physiol. Neurobiol. 191, 95-105. doi: 10.1016/j.resp.2013.11.005

Henderson, F., May, W. J., Gruber, R. B., Young, A. P., Palmer, L. A., Gaston, B., et al. (2013). Low-dose morphine elicits ventilatory excitant and depressant responses in conscious rats: role of peripheral $\mu$-opioid receptors. Open J. Mol. Integr. Physiol. 3, 111-124. doi: 10.4236/ojmip.2013.33017

Jiang, B., Huang, Z. J., Morales, B., and Kirkwood, A. (2005). Maturation of GABAergic transmission and the timing of plasticity in visual cortex. Brain Res. Rev. 50, 126-133. doi: 10.1016/j.brainresrev.2005.05.007

Kikuta, S., Iwanaga, J., Kusukawa, J., and Tubbs, R. S. (2019). Carotid sinus nerve: a comprehensive review of its anatomy, variations, pathology, and clinical applications. World Neurosurg. 127, 370-374. doi: 10.1016/j.wneu.2019.04.064

Kiwull, P., Kiwull-Schöne, H., and Klatt, W. (1976). "Interaction of central and peripheral respiratory drives: differentiation between the role of stimuli and afferents," in Acid-Base Homeostasis of Brain Extracellular Fluid and the Respiratory Control System, ed. H. H. Loeschcke (Stuttgart: Thieme), 146-156.

Kiwull-Schöne, H., Kiwull, P., Mückenhoff, K., and Both, W. (1976). The role of carotid chemoreceptors in the regulation of arterial oxygen transport under hypoxia with and without hypercapnia. Adv. Exp. Med. Biol. 75, 469-476. doi: 10.1007/978-1-4684-3273-2_55

Laferrière, A., Colin-Durand, J., and Moss, I. R. (2005). Ontogeny of respiratory sensitivity and tolerance to the mu-opioid agonist fentanyl in rat. Brain Res. Dev. Brain Res. 156, 210-217. doi: 10.1016/j.devbrainres.2005.03.002

Lai, C. H., Ma, C. W., Lai, S. K., Han, L., Wong, H. M., Yeung, K. W., et al. (2016). Maturation of glutamatergic transmission in the vestibulo-olivary pathway impacts on the registration of head rotational signals in the brainstem of rats. Brain Struct. Funct. 221, 217-238.

Liu, Q., Lowry, T. F., and Wong-Riley, M. T. (2006). Postnatal changes in ventilation during normoxia and acute hypoxia in the rat: implication for a sensitive period. J. Physiol. 577, 957-970. doi: 10.1113/jphysiol.2006.121970

López-Barneo, J., Ortega-Sáenz, P., Pardal, R., Pascual, A., and Piruat, J. I. (2008). Carotid body oxygen sensing. Eur. Respir. J. 32, 1386-1398. doi: 10.1183/ 09031936.00056408

Lowry, T. F., Forster, H. V., Pan, L. G., Korducki, M. A., Probst, J., Franciosi, R. A., et al. (1999a). Effect of carotid body denervation on breathing in neonatal goats. J. Appl. Physiol. 87, 1026-1034. doi: 10.1152/jappl.1999.87.3.1026

Lowry, T. F., Forster, H. V., Pan, L. G., Serra, A., Wenninger, J., Nash, R., et al. (1999b). Effects on breathing of carotid body denervation in neonatal piglets. J. Appl. Physiol. 87, 2128-2135. doi: 10.1152/jappl.1999.87.6.2128

Martin-Body, R. L., Robson, G. J., and Sinclair, J. D. (1985). Respiratory effects of sectioning the carotid sinus glossopharyngeal and abdominal vagal nerves in the awake rat. J. Physiol. 361, 35-45. doi: 10.1113/jphysiol.1985.sp01 5631
Martin-Body, R. L., Robson, G. J., and Sinclair, J. D. (1986). Restoration of hypoxic respiratory responses in the awake rat after carotid body denervation by sinus nerve section. J. Physiol. 380, 61-73. doi: 10.1113/jphysiol.1986.sp016272

Maxová, H., and Vízek, M. (2001). Biphasic ventilatory response to hypoxia in unanesthetized rats. Physiol. Res. 50, 91-96.

May, W. J., Gruber, R. B., Discala, J. F., Puskovic, V., Henderson, F., Palmer, L. A., et al. (2013a). Morphine has latent deleterious effects on the ventilatory responses to a hypoxic challenge. Open J. Mol. Integr. Physiol. 3, 166-180. doi: 10.4236/ojmip.2013.34022

May, W. J., Henderson, F., Gruber, R. B., Discala, J. F., Young, A. P., Bates, J. N., et al. (2013b). Morphine has latent deleterious effects on the ventilatory responses to a hypoxic-hypercapnic challenge. Open J. Mol. Integr. Physiol. 3, 134-145. doi: 10.4236/ojmip.2013.33019

McCooke, H. B., and Hanson, M. A. (1985). Respiration of conscious kittens in acute hypoxia and effect of almitrine bismesylate. J. Appl. Physiol. 59, 18-23. doi: 10.1152/jappl.1985.59.1.18

Mitchell, G. S., and Johnson, S. M. (2003). Neuroplasticity in respiratory motor control. J. Appl. Physiol. 94, 358-374. doi: 10.1152/japplphysiol.00523.2002

Mouradian, G. C., Forster, H. V., and Hodges, M. R. (2012). Acute and chronic effects of carotid body denervation on ventilation and chemoreflexes in three rat strains. J. Physiol. 590, 3335-3347. doi: 10.1113/jphysiol.2012.234658

Nattie, E. (2006). Why do we have both peripheral and central chemoreceptors? J. Appl. Physiol. 100, 9-10. doi: 10.1152/japplphysiol.01097.2005

Nurse, C. A. (2005). Neurotransmission and neuromodulation in the chemosensory carotid body. Auton. Neurosci. 120, 1-9. doi: 10.1016/j. autneu.2005.04.008

Nurse, C. A. (2010). Neurotransmitter and neuromodulatory mechanisms at peripheral arterial chemoreceptors. Exp. Physiol. 95, 657-667. doi: 10.1113/ expphysiol.2009.049312

Olson, E. B. Jr., Vidruk, E. H., and Dempsey, J. A. (1988). Carotid body excision significantly changes ventilatory control in awake rats. J. Appl. Physiol. 64, 666-671. doi: 10.1152/jappl.1988.64.2.666

Peers, C., and Buckler, K. J. (1995). Transduction of chemostimuli by the type I carotid body cell. J. Membr. Biol. 144, 1-9. doi: 10.1007/bf00238411

Pokorski, M., and Antosiewicz, J. (2010). Alterations in the hypoxic ventilatory response with advancing age in awake rats. J. Physiol. Pharmacol. 61, 227-232.

Prabhakar, N. R. (2000). Oxygen sensing by the carotid body chemoreceptors. J. Appl. Physiol. 88, 2287-2295. doi: 10.1152/jappl.2000.88.6.2287

Putnam, R. W., Conrad, S. C., Gdovin, M. J., Erlichman, J. S., and Leiter, J. C. (2005). Neonatal maturation of the hypercapnic ventilatory response and central neural CO2 chemosensitivity. Respir. Physiol. Neurobiol. 149, 165-179. doi: 10.1016/j.resp.2005.03.004

Roux, J. C., Peyronnet, J., Pascual, O., Dalmaz, Y., and Pequignot, J. M. (2000). Ventilatory and central neurochemical reorganisation of $\mathrm{O} 2$ chemoreflex after carotid sinus nerve transection in rat. J. Physiol. 522(Pt 3), 493-501. doi: 10. 1111/j.1469-7793.2000.t01-4-00493.x

Sapru, H. N., and Krieger, A. J. (1977). Carotid and aortic chemoreceptor function in the rat. J. Appl. Physiol. Respir. Environ. Exerc. Physiol. 42, 344-348. doi: 10.1152/jappl.1977.42.3.344

Sengupta, P. (2013). The laboratory rat: relating its age with human's. Int. J. Prev. Med. 4, 624-630.

Serra, A., Brozoski, D., Hedin, N., Franciosi, R., and Forster, H. V. (2001). Mortality after carotid body denervation in rats. J. Appl. Physiol. 91, 1298-1306. doi: 10.1152/jappl.2001.91.3.1298

Serra, A., Brozoski, D., Hodges, M., Roethle, S., Franciosi, R., and Forster, H. V. (2002). Effects of carotid and aortic chemoreceptor denervation in newborn piglets. J. Appl. Physiol. 92, 893-900. doi: 10.1152/japplphysiol.00819.2001

Sheikhbahaei, S., Turovsky, E. A., Hosford, P. S., Hadjihambi, A., Theparambil, S. M., Liu, B., et al. (2016). Astrocytes modulate brainstem respiratory rhythmgenerating circuits and determine exercise capacity. Nat. Commun. 9:370.

Sinclair, D., Purves-Tyson, T. D., Allen, K. M., and Weickert, C. S. (2014). Impacts of stress and sex hormones on dopamine neurotransmission in the adolescent brain. Psychopharmacology 231, 1581-1599. doi: 10.1007/s00213-013-3415-z

Sinclair, J. D. (1987). Respiratory drive in hypoxia: carotid body and other mechanisms compared. News Pharmacol. Sci. 2, 57-60. doi: 10.1152/ physiologyonline.1987.2.2.57

Smith, C. A., Blain, G. M., Henderson, K. S., and Dempsey, J. A. (2015). Peripheral chemoreceptors determine the respiratory sensitivity of central chemoreceptors 
to CO2: role of carotid body CO2. J. Physiol. 593, 4225-4243. doi: 10.1113/ JP270114

Smith, C. A., Forster, H. V., Blain, G. M., and Dempsey, J. A. (2010). An interdependent model of central/peripheral chemoreception: evidence and implications for ventilatory control. Respir. Physiol. Neurobiol. 173, 288-297. doi: 10.1016/j.resp.2010.02.015

Smith, C. A., Jameson, L. C., Mitchell, G. S., Musch, T. I., and Dempsey, J. A. (1984). Central-peripheral chemoreceptor interaction in awake cerebrospinal fluid-perfused goats. J. Appl. Physiol. 56, 1541-1549. doi: 10.1152/jappl.1984. 56.6.1541

Smith, C. A., Rodman, J. R., Chenuel, B. J., Henderson, K. S., and Dempsey, J. A. (2006). Response time and sensitivity of the ventilatory response to CO2 in unanesthetized intact dogs: central vs. peripheral chemoreceptors. J. Appl. Physiol. 100, 13-19. doi: 10.1152/japplphysiol.00926.2005

Smith, P. G., and Mills, E. (1980). Restoration of reflex ventilatory response to hypoxia after removal of carotid bodies in the cat. Neuroscience 5, 573-580. doi: 10.1016/0306-4522(80)90054-8

Song, G., Xu, H., Wang, H., Macdonald, S. M., and Poon, C.-S. (2011). Hypoxiaexcited neurons in NTS send axonal projections to Kölliker-Fuse/parabrachial complex in dorsolateral pons. Neuroscience 175, 145-153. doi: 10.1016/j. neuroscience.2010.11.06

Stunden, C. E., Filosa, J. A., Garcia, A. J., Dean, J. B., and Putnam, R. W. (2001). Development of in vivo ventilatory and single chemosensitive neuron responses to hypercapnia in rats. Respir. Physiol. 127, 135-155. doi: 10.1016/ s0034-5687(01)00242-0

Suguihara, C., Hehre, D., and Bancalari, E. (1994). Effect of dopamine on hypoxic ventilatory response of sedated piglets with intact and denervated carotid bodies. J. Appl. Physiol. 77, 285-289. doi: 10.1152/jappl.1994.77.1.285

Sun, M. K., and Reis, D. J. (1994). Hypoxia selectively excites vasomotor neurons of rostral ventrolateral medulla in rats. Am. J. Physiol. 266, R245-R256. doi: 10.1152/ajpregu.1994.266.1.R245

Tahayori, B., and Koceja, D. M. (2012). Activity-dependent plasticity of spinal circuits in the developing and mature spinal cord. Neural Plast. 2012:964843. doi: $10.1155 / 2012 / 964843$

Teppema, L. J., and Dahan, A. (2010). The ventilatory response to hypoxia in mammals: mechanisms, measurement, and analysis. Physiol. Rev. 90, 675-754. doi: 10.1152/physrev.00012.2009
Tse, A., Yan, L., Lee, A. K., and Tse, F. W. (2012). Autocrine and paracrine actions of ATP in rat carotid body. Can. J. Physiol. Pharmacol. 90, 705-711. doi: 10.1139/y2012-054

Turovsky, E., Theparambil, S. M., Kasymov, V., Deitmer, J. W., Del Arroyo, A. G., Ackland, G. L., et al. (2016). Mechanisms of $\mathrm{CO} 2 / \mathrm{H}+$ sensitivity of astrocytes. J. Neurosci. 36, 10750-10758. doi: 10.1523/JNEUROSCI.1281-16. 2016

Vizek, M., Pickett, C. K., and Weil, J. V. (1987). Biphasic ventilatory response of adult cats to sustained hypoxia has central origin. J. Appl. Physiol. 63, 1658-1664. doi: 10.1152/jappl.1987.63.4.1658

Wakai, J., Takamura, D., Morinaga, R., Nakamuta, N., and Yamamoto, Y. (2015). Differences in respiratory changes and Fos expression in the ventrolateral medulla of rats exposed to hypoxia, hypercapnia, and hypercapnic hypoxia. Respir. Physiol. Neurobiol. 215, 64-72. doi: 10.1016/j.resp.2015. 05.008

Wallenstein, S., Zucker, C. L., and Fleiss, J. L. (1980). Some statistical methods useful in circulation research. Circ. Res. 47, 1-9. doi: 10.1161/01.res.47.1.1

Xie, A., Skatrud, J. B., Khayat, R., Dempsey, J. A., Morgan, B., and Russell, D. (2005). Cerebrovascular response to carbon dioxide in patients with congestive heart failure. Am. J. Respir. Crit. Care Med. 172, 371-378. doi: 10.1164/rccm. 200406-807OC

Young, A. P., Gruber, R. B., Discala, J. F., May, W. J., McLaughlin, D., Palmer, L. A., et al. (2013). Co-activation of $\mu$ - and $\delta$-opioid receptors elicits tolerance to morphine-induced ventilatory depression via generation of peroxynitrite. Respir. Physiol. Neurobiol. 186, 255-264. doi: 10.1016/j.resp.2013. 02.028

Conflict of Interest: The authors declare that the research was conducted in the absence of any commercial or financial relationships that could be construed as a potential conflict of interest.

Copyright (c) 2020 Getsy, Coffee and Lewis. This is an open-access article distributed under the terms of the Creative Commons Attribution License (CC BY). The use, distribution or reproduction in other forums is permitted, provided the original author(s) and the copyright owner(s) are credited and that the original publication in this journal is cited, in accordance with accepted academic practice. No use, distribution or reproduction is permitted which does not comply with these terms. 